\title{
Safely Testing the Alarm: Close Others' Responses to Personal Positive Events
}

\author{
Shelly L. Gable and Courtney L. Gosnell \\ University of California, Santa Barbara
}

\author{
Natalya C. Maisel \\ Veterans Affairs Palo Alto Health Care System, Palo Alto, \\ California
}

\author{
Amy Strachman \\ eHarmony Labs, Santa Monica, California
}

\begin{abstract}
Previous research has shown that receiving social support in the face of negative events (i.e., enacted support) is sometimes correlated with positive outcomes, sometimes unrelated to outcomes, and sometimes associated with negative outcomes. However, people's perception that they have high-quality support available to them when they have a stressor (i.e., perceived support) is consistently and strongly associated with better health, well-being, and relationship functioning. However, both enacted and perceived support available in response to positive event disclosures are consistently associated with positive outcomes. In 2 studies, we examined why enacted support for negative events has such a spotty record and compared it with enacted support for positive events; a third study examined how support for positive events may be a major contributor to perceived availability of effective support for negative events. The results showed that providing responsive support to negative events is particularly difficult; received support for negative events disclosures (but not positive event disclosures) involves substantial drawbacks and risks, especially when that support is not responsive to the recipient's needs; and that enacted support for positive events was a better predictor of later perceptions of the quality of available support for stressors than enacted support for negative events. Findings are discussed in terms of implications for the social support literature and how positive relationship processes influence health and well-being, not only directly but also indirectly by providing critical information regarding the availability of others if a problem occurs.
\end{abstract}

Keywords: close relationships, social support, capitalization, relationship satisfaction, well-being

But friendship is precious, not only in the shade, but in the sunshine of life, and thanks to a benevolent arrangement, the greater part of life is sunshine.-Thomas Jefferson

There is a contradiction in the social support literature, one that is often overlooked or underplayed. The crux of the contradiction is as follows. Perceived availability of high-quality support, the perception that others will be there for us during times of stress, is associated with positive health and well-being (Cohen \& Wills, 1985; Sarason, Sarason, \& Gurung, 1997; Uchino, Cacioppo, \&

This article was published Online First August 13, 2012.

Shelly L. Gable and Courtney L. Gosnell, Department of Psychology, University of California, Santa Barbara; Natalya C. Maisel, Center for Health Care Evaluation, Veterans Affairs Palo Alto Health Care System, Palo Alto, California; Amy Strachman, eHarmony Labs, Santa Monica, California

Studies 1 and 2 were supported by National Science Foundation Grant CAREER BCS-0444129, and Study 3 was supported by a Young Scholars Grant from the Templeton Foundation and Positive Psychology Network, both awarded to Shelly L. Gable.

Correspondence concerning this article should be addressed to Shelly L. Gable, Department of Psychology, University of California, Santa Barbara, 3822 Psychology East, Santa Barbara, CA 93110. E-mail: gable@ psych.ucsb.edu
Kiecolt-Glaser, 1996). However, enacted support, the receipt of actual support from others during times of stress, has been weakly correlated with positive outcomes, unrelated to outcomes, or, worse, associated with negative outcomes (e.g., Bolger, Zuckerman, \& Kessler, 2000; Collins, Dunkel-Schetter, Lobel, \& Scrimshaw, 1993; Kaul \& Lakey, 2003). Moreover, the degree to which actual enacted support transactions contribute to the perceived availability of effective support is unclear, as measures of the two are only weakly correlated (e.g., Haber, Cohen, Lucas, \& Baltes, 2007). In short, although we are confident that perceptions of available support in times of stress are associated with a symphony of positive outcomes, actually receiving support from others is not reliably associated with positive outcomes, nor is it strongly related to perceptions of availability of the very support in question.

This leaves a complex two-pronged puzzle: Researchers need to first understand why enacted support does not work the same as perceived support and also unpack from where perceptions of support availability actually originate (Coyne \& DeLongis, 1986). In the present article, we contend (as others have) that provisions of social support for stressors pose risks to the support recipient and the relationship (e.g., Shrout, Herman, \& Bolger, 2006); providing effective support to a person in distress can be difficult (e.g., Dunkel-Schetter \& Bennett, 1990); and enacted support is not the primary contributor to perceptions of the availability of support (e.g., Haber et al., 2007; Kaul \& Lakey, 2003; Lakey \& 
Orehek, in press). However, we also contend that support provided in transactions that are not stressors, such as in response to a positive or joyful event, poses fewer risks to the recipient and the relationship, is easier to provide effectively, and ironically contributes directly to perceptions of the availability of support in times of stress. Thus, the positive event context provides critical information about the integrity of the relationship and the ability of a partner to provide effective support in a relatively safe situation, akin to pushing the test button on a smoke detector. In the present article, we present three studies in which we tested our hypotheses by assessing both support provided for negative events and support provided for positive events and comparing them and their associations with outcomes to one another.

\section{In the Shade of Life}

\section{Perceived Availability and Quality of Support for Negative Events and Stressors}

One of the most consistent findings in the field is that perceiving that helpful others will be there for you in times of stress is associated with better physical and mental health (Cohen, 1988; Cohen \& Wills, 1985; Kaul \& Lakey, 2003; Lakey \& Cassady, 1990; Uchino et al., 1996). For example, perceived availability of effective support has been associated with reduced levels of anxiety and depression during stressful periods (Fleming, Baum, Gisriel, \& Gatchel, 1982), more positive adjustment to diseases (Holahan, Moos, Holahan, \& Brennan, 1997; Stone, Mezzacappa, Donatone, \& Gonder, 1999), and reduced heart rate and blood pressure response during a stressful speech task (Smith, Ruiz, \& Uchino, 2004).

Perceptions of the availability of support are also closely tied to relationship quality, such that high relationship satisfaction and intimacy are strongly correlated with perceptions of the availability of social support (e.g., Kaul \& Lakey, 2003). In fact, many theories of relationship intimacy and satisfaction include the importance of perceptions that the partner will respond to their needs as a critical component (e.g., Reis, Clark, \& Holmes, 2004). Moreover, people who have difficulty feeling secure and satisfied in close relationships also perceive that others will be less available to them in times of need (e.g., Blain, Thompson, \& Whiffen, 1993; Ognibene \& Collins, 1998; Rholes, Simpson, Campbell, \& Grich, 2001). In summary, perceptions of the availability of social support are closely tied to personal outcomes and relationship functioning.

\section{Received Support for Negative Events and Stressors}

Given the findings on perceived availability of support, it would seem logical that support enacted by others, called enacted or received support, would also be beneficial to the support recipient. However, research has shown that this is not often the case (e.g., Barbee, Derlega, Sherburne, \& Grimshaw, 1998; Dakof \& Taylor, 1990; Gleason, Iida, Bolger, \& Shrout, 2003). That is, when people receive support from others, they often report decreases in health and well-being. One complicating factor in these studies is that stress and health status are likely linked such that those who are in worse health or under more stress may receive more support. However, studies that do focus on such factors show that the possible negative effect of received support goes beyond this explanation (e.g., Forster \& Stoller, 1992; Rini, Schetter, Hobel, Glynn, \& Sandman, 2006).

Researchers have examined several possible explanations of these apparent risks of enacted support. One set of explanations revolves around the unintended consequences of received support. Specifically, researchers have proposed that receiving support from others can bring costs because it may be a blow to one's self-esteem, as a vulnerability or weakness has been made salient, or it may draw more attention to the problem (e.g., Bolger et al., 2000). In addition, receiving support may lead the recipient to feel overly indebted, incompetent, or weak (Gleason et al., 2003; Shrout et al., 2006). In essence, the costs of enacted support undermine the benefits, benefits such as practical help and emotional comfort (see Sarason et al., 1997).

The notion that enacted support carries risks has received considerable backing and has led to the idea that the most effective support is support that is not recognized as such by the recipient. For example, Bolger and colleagues (2000) conducted a study examining the effects of actual support interactions. They found that stressed individuals reported better outcomes (e.g., lower anxiety) on days that their partner reported providing support, but they did not report receiving support themselves (which the researchers called "invisible support") compared with days the stressed recipient reported receiving support from the partner (called "visible support"). One explanation for these intriguing findings is that invisible support avoids the unintended risks of support provision while maximizing the potentials gains.

Another set of explanations for the possible negative consequences of receiving support revolve around the challenges of providing high-quality, effective support. That is, researchers have found that actual support received can miss the mark, or not be delivered in a skilled manner; consequently, the support is unhelpful and perhaps even harmful to the recipient (e.g., DunkelSchetter \& Bennett, 1990; Lehman, Ellard, \& Wortman, 1986; Rafaeli \& Gleason, 2009). For example, in a group of pregnant women, Rini and colleagues (2006) found that a variety of factors, such as match to current needs, skill of delivery, reflections on recipient's self-concept, and apparent burden of transaction, contributed to whether or not recent support transactions (tangible, informational, and emotional) were perceived as effective. ${ }^{1}$ Moreover, more effective social support was associated with less pregnancy-related distress both concurrently and prospectively.

This study and other related findings (e.g., Dakof \& Taylor, 1990; Helgeson \& Cohen, 1996) are informative on many levels, but there are two points that we think are most relevant to our present premise. First, studies show a linear association between the effectiveness of enacted support and outcomes, essentially indicating that more effective support was associated with lower anxiety and less effective support was associated with greater anxiety and distress. Second, many factors determine whether enacted support was perceived as actually helpful. Thus, it is likely

\footnotetext{
${ }^{1}$ Rini and colleagues (2006) also found that several relationship factors (e.g., intimacy) and personal factors (e.g., attachment style of the receiver) influenced ratings of the effectiveness of enacted support. Clearly, evaluations of whether a support transaction is viewed as helpful go beyond the actual support provision episode itself. This is a point we return to at the end of the introduction and again in the Discussion.
} 
that delivering high-quality support to someone in need is a challenging task for the provider. Getting it right seems to require correctly nailing a laundry list of features in the provision of support, and only support that is either perceived as effective and high quality or is not perceived at all (invisible) is actually associated with positive outcomes for the recipient.

\section{The Association Between Perceived Availability of Support and Received Support}

How people form and maintain their perceptions of the quality of support available to them in times of stress is somewhat of a mystery. Several researchers have aptly concluded that the two are indeed separate constructs that likely have different antecedents (e.g., Uchino, 2009; Wills \& Shinar, 2000). In fact, a recent theoretical article has proposed that perceived availability of support stems from ordinary interactions in which people regulate their emotions, thoughts, and behaviors, and not necessarily instances centered on stress and coping (Lakey \& Orehek, 2011). Empirical reviews are consistent with these conclusions as the correlation between measures of perceived and received support have varied widely but are typically found to be less than .30 (e.g., Lakey et al., 2002), and several major studies have reported the association to be essentially zero (e.g., $r=.01$; Sandler \& Barerra, 1984). Haber et al. (2007) recently conducted a meta-analysis that evaluated the correlations between a particular measure of enacted support (the Inventory of Socially Supportive Behaviors; Barrera, Sandler, \& Ramsay, 1981) and a variety of measures of perceived availability of support. Across the 23 studies in this article, the average correlation between enacted and perceived availability of support was .32. Although this correlation suggests the two measures have significant overlap, in reality enacted support and perceived support shared only about $10 \%$ of the variance. This is especially concerning because the measures have considerable item overlap, and a certain percentage of shared variance should be expected based solely on the similarity of item wording. Moreover, Haber and colleagues observed that studies that used measures of perceived support with references to different types of specific support (e.g., emotional, informational, and tangible) reported higher correlations with enacted support measures than studies that used measures of general perceptions of the availability of close others in times of stress. This led the authors to speculate that some measures of perceived support may encourage participants to consider recent specific episodes of support when forming their answers, inflating the estimated correlation.

\section{In the Sunshine of Life}

\section{Support for Positive Events and Successes}

Thankfully, as Jefferson noted, because of a "benevolent arrangement," providing support to someone is not the only opportunity for meaningful interactions. In fact, good things happen every day. Some positive events are routine, such as passing a pop quiz, finishing a project at work, or hearing the words "I love you" from a 2-year-old child. Other positive events are major, such as making the basketball team, landing that job, or seeing your child take her or his first steps. Previous work has shown that one of the most important ways that people react to positive events is to share their good news with others, a process called capitalization (Langston, 1994). That is, they also seek "support" for the positive events in their lives, and like support for negative events, they most often seek it from close others (Gable, Reis, Impett, \& Asher, 2004). For example, people shared their positive events with close others (such as friends, romantic partners, family members) $97 \%$ of the time, and only $3 \%$ of the time did they report sharing the event with a nonclose other, such as an acquaintance or a coworker (Gable et al., 2004; Study 4).

Although research has shown that there are both personal and interpersonal benefits derived merely from the act of sharing (Gable et al., 2004), the response of the other is an important predictor of outcomes for the individual and the relationship. Gable and Reis (2010) have argued that this is because the response to a positive event disclosure conveys two valuable pieces of information to the person disclosing the positive event: It reflects the responder's assessment of the event itself, including the implications the event has for the discloser. Second, but likely equally impactful, the response indicates the degree to which an interaction partner takes an interest in and derives pleasure from the discloser's personal well-being and growth.

When a positive event is shared, the person with whom it is shared can respond in several different ways. Just as Rusbult and colleagues found in their research on responses to negative partner behavior (e.g., Rusbult, Zembrodt, \& Gunn, 1982), responses to positive event disclosures have also been found to vary on at least two important dimensions. First, they can vary on a continuum from active to passive. That is, the responder can show interest, attention, or involvement when the event is shared (active), or the responder can be reserved, distracted, or detached in his or her reply (passive). The response can also vary on a continuum from constructive to destructive. Specifically, the responder can be positive and supportive or he or she can be negative and unsupportive. These two dimensions are independent and thus yield four different prototypical responses: active-constructive (reacting enthusiastically, asking questions, elaborating), passive-constructive (conveying warmth and satisfaction quietly and reservedly), active-destructive (pointing out the negative aspects, downplaying the significance of the event), and passive-destructive (ignoring the disclosure, turning the conversation onto a different topic).

Our previous work in several studies using multiple methods has found that only active-constructive responses were positively associated with good outcomes; active-destructive, passivedestructive, and passive-constructive were all negatively associated with good interpersonal and intrapersonal outcomes (Gable et al., 2004; Reis et al., 2010). It is important to note that the effects reported in the literature are above and beyond the importance of the event itself in the eyes of the discloser, so they cannot be explained by the likely fact that responders react more enthusiastically to bigger events. Previous work has also found strong evidence that active-constructive, and not passive or destructive, responses to capitalization attempts have a positive impact on close relationships. Studies of dating and married couples found that reporting that one's partner typically responds in an activeconstructive manner was associated with greater relationship satisfaction, trust, and intimacy, daily relationship satisfaction, positive activities, and fewer daily conflicts. However, reporting that one's partner typically responds in a passive-constructive, activedestructive, or passive-destructive manner was consistently negatively correlated with these outcomes (Gable, Gonzaga, \& Strach- 
man, 2006; Gable et al., 2004). Behavioral observation studies of established relationships and experimental manipulations with strangers have yielded the same results. Most relevant to the present research, Shorey and Lakey (2011) reported that perceptions of typical capitalization responses were correlated with perceived availability of support for negative events.

\section{Perceived and Received Capitalization Support}

Unlike the literature on social support for negative events, previous research has found no contradictions or inconsistent findings between perceived availability of effective capitalization support and received capitalization support. That is, whether people are asked to describe the quality of the capitalization support available to them or specific instances of capitalization that are reported or observed, the same pattern of results are found. For both perceived and received capitalization support, activeconstructive responding is associated with positive personal and relationship outcomes, and passive or destructive responding is associated with negative personal and relationship outcomes.

Another distinction between received support for positive events and received support for negative events is that previous research has found no unintended drawbacks of received capitalization. Unlike the literature described above (e.g., Bolger et al., 2000; Gleason et al., 2003), there is no evidence that drawing attention to the event is bad (on the contrary, it is beneficial) or that receiving positive event support makes one feel weak, indebted, or is a blow to one's self-esteem (again to the contrary, it enhances feelings of self-worth; Reis et al., 2010). Thus, there seem to be fewer risks involved with enacted capitalization than enacted social support.

Finally, in the context of capitalization responses, the person sharing the event has experienced a positive event, and therefore a good response to that event can play a role in the person making the most of it. Thus, there is potential for the receiver to move beyond his or her baseline and flourish (Gable \& Haidt, 2005). This is different from the traditional social support context in which the seeker is likely below his or her baseline as a result of the negative event or stressor. Even a very good response has the challenge of bringing the person from a negative state to a positive state.

\section{The Role of Responsiveness}

One issue in comparing support provided for positive events with support provided for negative events is that the behaviors that are perceived as effective and supportive are likely not the same in the two situations. In order to compare the two contexts, it is helpful to think about why certain behaviors are viewed as supportive in each context. That is, we need to examine a common mediating mechanism that leads to a behavior being perceived as effective and supportive or ineffective and unhelpful. That mechanism is perceived responsiveness to the self (Maisel, Gable, \& Strachman, 2008; Murray, Holmes, \& Collins, 2006; Reis et al., 2004). Perceived responsiveness to the self is the idea that the relationship partner understands, validates, and cares for "core ... features of the self" (Reis et al., 2004, p. 203).

Across many theoretical approaches to relationships (e.g., attachment theory, communal relationships theory), perceived responsiveness to the self, or "perceived responsiveness" for short, has been identified as a central and critical determinant of rela- tionship functioning (Murray et al., 2006). In terms of intrapersonal outcomes, perceived responsiveness is a core component of many approaches to understanding the formation of the self and the maintenance of self-esteem, as is found in constructs such as reflected appraisals and in sociometer theory (Chen, Boucher, \& Tapias, 2006; Leary, 2005). Moreover, many researchers have specifically conceptualized effective social support for negative events as support that is responsive to the self, and empirical reviews substantiate that claim (e.g., Murray et al., 2006; Rafaeli \& Gleason, 2009; Reis et al., 2004).

When enacted support is perceived to be responsive to the self, it predicts more positive outcomes, and when it is perceived to be unresponsive to the self, more negative outcomes occur. In a recent study, Maisel and Gable (2009) found that received support during a stressful event, both visible and invisible, was associated with positive outcomes for the recipient and the close relationship when it was perceived or intended to be responsive-understanding, validating, and caring. Conversely, when support was low in responsiveness, it was associated with no benefits or even negative outcomes. Thus, previous research that has not considered the quality of enacted social support (i.e., how responsive the support was) cannot adequately address the consequences of that support. Similarly, active-constructive capitalization responses convey understanding, validation, and caring (i.e., responsiveness) and are viewed as supportive and effective. Passive or destructive responses to capitalization attempts are not responsive and thus neither supportive nor effective.

\section{The Present Research}

The overarching goal of the present research was to compare the implications of the responses of close others with positive event disclosures and negative event disclosures. Specifically, we were interested in the ways these specific episodes of enacted "support" were similar and different, as well as how they each contributed to perceptions of the future availability of support for stressful events, because it is this variable that is so strongly and positively related to health and well-being in the literature. We predicted that the process that unfolds in the context of negative event disclosures differed from the process that unfolds in the context of the positive event disclosures. Specifically, we predicted that when a negative event is shared, the response of the partner is viewed through a negatively biased lens rendering well-intentioned support provisions less effective. Moreover, because the discloser is already in distress, ineffective (nonresponsive) support is particularly detrimental to the individual's well-being and his or her perceptions of the quality of the relationship, and responsive support at best brings the discloser back to baseline. In the end, on average these support transactions have little effect on perceptions of the future availability of support. However, when positive events are shared, the response of the partner is viewed through a positively biased lens rendering well-intentioned support provisions as highly effective and even poorly intentioned ones as benign. Because the positive event puts the discloser above baseline, the other's response at worst returns him or her to baseline levels, and at best raises him or her even farther above baseline levels of well-being and relationship satisfaction. In the end, responsive capitalization transactions are encoded as particularly effective and thus contribute substantially to perceptions of the future availability of support. 
Although we focused our discussion and model on the role of context, particularly the broader context (stressor vs. positive event), we acknowledge that differences between relationships (e.g., overall levels of responsiveness in the relationship) also affect the perception and effect of specific transactions. We return to a fuller consideration of this in the Discussion and control for this possibility in our primary analyses to rule out the effect as an explanation of our predicted pattern of findings.

We designed the present studies to test three distinct but interdependent hypotheses. In Study 1, we tested the hypothesis that recipients viewed responses to negative event disclosure less favorably and experienced more negative feelings about that response than responses to positive events, even when intentions to be supportive were equal. In Study 2, we tested the hypothesis that responding poorly (i.e., low responsiveness) to a close other's negative event carries considerable risks to the recipient and the relationship between the recipient and responder, whereas responding poorly to a close other's positive events involves less severe risks. On the flipside, we also predicted that responding well to a close other's negative event would have a smaller yield (less gains) than responding well to a close other's positive event. Finally, in Study 3, we tested the hypothesis that because of the risks and difficulties inherent in actually responding to negative events, responses to positive events would be more strongly related to later perceptions of available support for stressors.

\section{Study 1}

\section{Method}

Participants. Participants were 38 heterosexual couples (76 individuals) recruited through a university paid-subject pool, ranging in age from 17 to $28(M=19.64, S D=1.58)$. Participants had to be dating a minimum of 1 month to qualify for the study, and they were dating on average for 11.78 months (range $=1-48$ months). They were paid $\$ 25$ for full completion of the study (\$5 for the initial session and $\$ 20$ for completion of the 10 daily records). Payment was prorated for participants who did not complete all daily records.

Procedure. Participants came into the lab with their partner to complete demographic measures, a measure of general perceived responsiveness, and to receive instructions for the daily experience portion of the study. For the next 10 days, participants were e-mailed a hyperlink to the nightly online diary questionnaire by 5:00 p.m. each day and were instructed to complete it right before going to bed that evening, separately from their partner. To ensure privacy and the integrity of the data, participants used an individual password to log onto the website and complete the survey. Participants were sent a reminder the following morning if they had not completed the survey, and they had until 11:00 a.m. to complete the survey before it was closed. After 10 days, they returned to the lab for an exit interview and to receive payment. Participants completed a total of 668 records, an average of 8.56 per person.

\section{Measures.}

Daily personal positive and negative events: Perceived responsiveness. Participants reported on whether they had a personal positive event or success that they shared with their partner that day, and, if so, they provided a brief (a few words) description of the event. Participants were asked to only report personal events and not those that involved the partner or concerned the relationship. They then rated the perceived responsiveness of their partner to their disclosure using three questions adapted from the three core elements of Reis's (2003) Responsiveness Measure. The prompt was: "When I told my partner about a concern/positive event ...": and the three items were: "My partner understood me"; "My partner made me feel like he/she valued my abilities and opinions"; and "My partner made me feel cared for." All items were rated on a 5-point Likert scale $(1=$ not at all, $5=$ very much). These items were aggregated to create a positive event perceived responsiveness score $(\alpha=.94)$. Participants reported sharing a positive event on $29 \%$ of the days they completed a record.

Participants also reported on whether they had a personal negative event or concern that they shared with their partner that day. If they did, they provided a brief description of the event and then rated the responsiveness of their partner to the disclosure using the same three-item scale they used when reporting a positive event. These items were aggregated to create a negative event perceived responsiveness score $(\alpha=.97)$. Participants reported sharing a negative event on $17 \%$ of the days they completed a record.

Daily personal positive and negative events: Feelings about interaction. For each shared personal positive event and personal negative event, participants were asked to indicate the extent to which they experienced a variety of feelings. Specifically, for each positive or negative event they shared with their partner, they reported how much the interaction with the partner led them to feel supported, thankful, admiration (for partner), indebted, and resentment on a $0-6$ scale $(0=$ not at all, $6=$ very much $)$ as a result of their partner's response to their event disclosure.

Daily personal positive and negative events: Support seeking and importance of events. For each personal positive event and personal negative event, participants were asked to indicate the extent to which they sought support from their partner when they shared the event using a 1-4 scale $(1=I$ was not looking for any support from my partner, $2=I$ was open to support from my partner, but wasn't expecting it, $3=I$ was looking for some support from my partner, $4=I$ was counting on my partner to provide me with support). Participants also rated how important the event was to them using a $1-9$ scale $(1=$ not very important, $9=$ very important).

Daily partners' positive and negative events: Intended responsiveness. Participants reported on whether their partner shared a positive event or success with them that day, and if so, they provided a brief description of the event. Participants then reported on how responsive they intended to be when their partner shared the event. They completed a modified version of the three-item Perceived Responsiveness scale. The items were "I tried to understand my partner"; "I tried to make my partner feel like I valued his/her abilities and opinions"; "I tried to make my partner feel care for," and they used the same 5-point Likert response scale $(1=$ not at all, $5=$ very much $)$. These items were aggregated to create a positive event intended responsiveness score $(\alpha=.94)$. Participants reported that their partners shared a positive event with them on $18 \%$ of the days they completed a record.

Participants also reported on whether their partner shared a negative event or concern with them that day, and if so, they provided a brief description of the event. Participants then reported on how responsive they intended to be when their partner shared the event using the same measures described above. These items were aggregated to create a negative event intended responsive- 
ness score $(\alpha=.93)$. Participants reported that their partners shared a negative event with them on $9 \%$ of the days they completed a record.

Overall typical perceived partner responsiveness. During the initial session, participants completed a one-time measure of General Responsiveness (Reis, 2003), which includes 18 items such as "My partner really listens to me"; "My partner is an excellent judge of my character"; and "My partner is responsive to my needs." Responses were rated on a 7-point Likert scale ranging from 1 (Not at All True/Never True) to 5 (Very Much True/True all the Time). The mean score was $5.87(S D=1.13)$ for men and 5.90 $(S D=0.98)$ for women. The scale had good reliability $(\alpha=.97)$.

\section{Results}

Data analytic strategy. Our primary hypothesis was that, on average, participants would report perceiving less responsiveness and less positive feelings about the interaction when sharing a negative event than when they shared a positive event. However, we did not predict that participants would intend to be less responsive when their partners shared a negative event than when they shared a positive event. As noted, participants reported sharing positive events on $29 \%$ of days, but partners reported them sharing on $18 \%$ of days. Similarly, participants reported sharing negative events on $18 \%$ of days, but partners reported they did so on only $9 \%$ of the days. Moreover, even when the partner reported that the participant shared an event, it was not necessarily the case that the participant reported sharing an event that day (the situation Bolger and colleagues, 2000, call "invisible support"), nor was it necessarily the case that that they were referring to the same event. In short, comparison of individual days (i.e., the difference between perceived and intended responsiveness for particular events) was not ideal. ${ }^{2}$ Therefore, we aggregated the daily perceived responsiveness, feelings about the interaction, and intended responsiveness scores across the daily experience records to assess how participants perceived sharing positive and negative events across the 10 days. In addition, according to criteria laid out by Kenny, Kashy, and Cook (2006), we assumed the data to be nonindependent as the correlations between couple members' scores on the nine dependent variables averaged .29 (range $=.15-.68$ ). Therefore, we aggregated scores within couples and analyzed a single score for each couple. ${ }^{3}$ However, because not each participant had a score on each variable, in some cases a couple's score was calculated from only one member. For example, if Bob reported that Mary shared two negative events during the study, but Mary did not report that Bob shared any negative events, then we used Bob's scores on the variables regarding negative event disclosures to represent the couple. However, if Mary also reported that Bob shared at least one negative event during the study, then we used an average of Bob and Mary's score on the variables regarding negative event disclosures to represent the couple. For some of the 38 couples, neither member reported the event type in question, and therefore no score could be calculated. For the variables concerning disclosure of own personal positive events, $n=37$, disclosure of own personal negative events, $n=34$, partners' disclosure of positive events, $n=35$, partners' disclosure of negative events, $n=24$. $^{4}$

Personal positive and negative events: Perceived responsiveness. We tested the hypothesis that, on average, participants would perceive more responsiveness from their partners when they shared a positive event than when they shared a negative event by conducting a paired samples $t$ test. As expected, we found that participants perceived more responsiveness from their partners when they shared a positive event $(M=4.24)$ than when they shared a negative event $(M=3.65) .{ }^{5}$ See Table 1 . We repeated this analysis controlling for overall ratings of typical responsiveness, and the effect remained significant, $F(1,32)=6.31, p<.05$.

Personal positive and negative events: Feelings about interaction. We tested the hypothesis that, on average, participants would have more positive (and less negative) feelings about the interaction when they shared a positive event than when they shared a negative event using paired samples $t$ tests. See Table 1 section labeled "Feelings about the interaction." When participants shared a positive event, compared with when they shared a negative event, they were significantly more thankful, and they felt significantly more supported, admiration, and less resentment. Contrary to our expectations, feelings of indebtedness did not differ significantly in positive and negative event disclosures.

Personal positive and negative events: Support seeking and importance of events. In order to investigate whether there was a fundamental difference between positive and negative event disclosures in the amount of support participants were seeking and expecting from their partners, we conducted a paired samples $t$ test on the amount of support sought from the partner in question. As expected, we found that the amount of support participants were seeking from their partners did not differ depending on whether they shared a positive or negative event; see Table 1 . To investigate whether participants rated their positive and negative events differently on how important the event was to them, we conducted a paired samples $t$ test on the importance ratings of events. Again, positive and negative events did not significantly differ in importance ratings (see Table 1). Thus, our analyses showed that the observed differences in perceptions of responsiveness and feelings about the interaction between positive and negative event disclosures were not due to negative events eliciting stronger feelings because they were more important than positive events, or because the partner's behavior was more

\footnotetext{
${ }^{2}$ Nevertheless, to satisfy our curiosity, we conducted a tentative analysis by creating a perceived minus intended score for all days that both partners reported that an event was shared by participants $(n=70)$ and created an average difference score across days for each couple. For the 10 couples who had data in both positive and negative event categories, the mean for positive events was 0.01 and for negative events was -0.45 ; a paired samples $t$ test was marginally significant $(p=.08)$. This analysis is consistent with the main analyses-perceived responsiveness for negative events was lower than intended ( -.45 on average), whereas the difference between perceived and intended responsiveness for positive events was virtually zero $(0.01)$.

${ }^{3}$ We also ran analyses assuming no dependence in the data, using each participant's scores $(n=76)$, and the pattern of results were the same (significant effects remained significant; nonsignficant ones remained nonsignificant).

${ }^{4}$ Kenny and colleagues (2006) also suggest that a minimum of 35 dyads is needed to have enough power to detect nonindependence and to assume nonindepenence if $N$ is less than 35 .

5 Analyses from this data set also appeared in Maisel and Gable (2009). The previous article focused on examining the role of responsiveness in invisible and visible social support for negative event transactions only. Although the analyses presented here are distinct, the present results are consistent with the conclusions of the previous article.
} 
Table 1

Means, Standard Deviations, and t Tests for Perceived Responsiveness, Feelings About the Interaction, and Intended Responsiveness for Positive and Negative Event Disclosures in Study 1

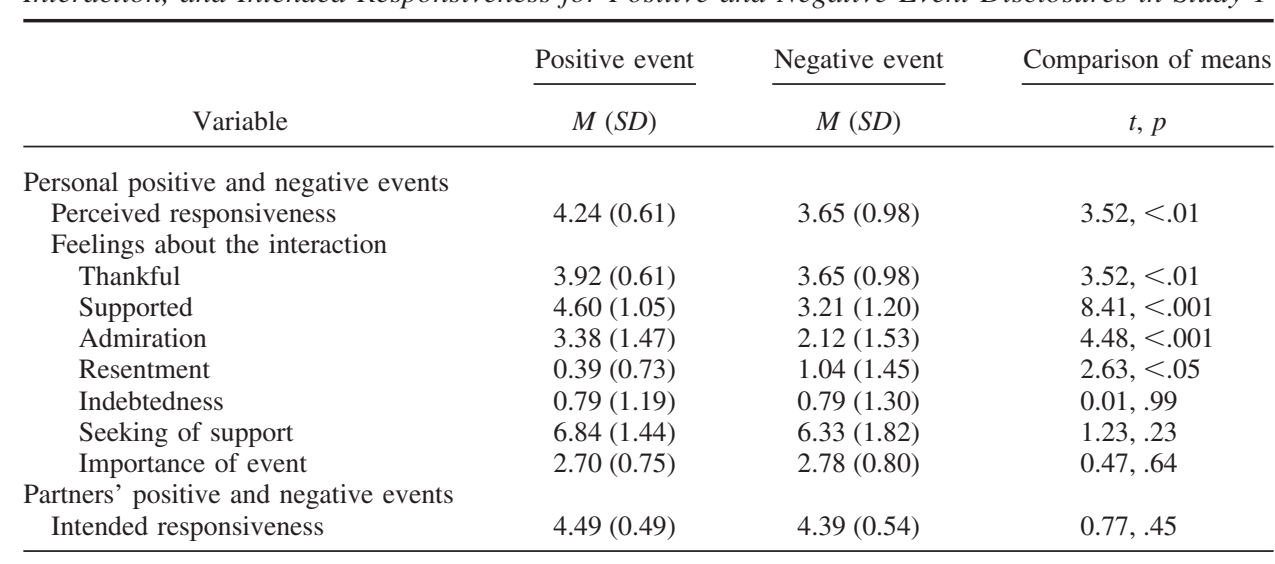

Note. $\quad d f=33$ for personal event $t$ tests and $d f=22$ for the partners' event $t$ test.

disappointing due to increased expectations of support in the negative event context compared with the positive event context.

Partners' positive and negative events: Intended responsiveness. We also examined whether, on average, participants' intended responsiveness toward their partners would differ depending on whether the partner shared a positive event or negative event by conducting a paired samples $t$ test. As expected, participants did not differ in the level of responsiveness they intended to provide to their partners' disclosures of positive and negative events $(M=4.49$ vs. $M=4.39$; see Table 1$)$.

\section{Discussion}

The results of Study 1 were consistent with our hypotheses. We found that, on average, across the 10-day study, participants rated their partners' responsiveness in reaction to their positive events disclosures higher than they rated their partners' responsiveness in reaction to their negative event disclosures. They also felt more supported by, thankful of, admiration for, and less resentful toward their partners when they shared a positive event than a negative event. These effects were not attributable to differences in the amount of support participants sought from their partners when they disclosed positive and negative events, the importance of the events, or the intended responsiveness of their partners. Contrary to our expectation, participants' feelings of indebtedness did not differ by event type disclosed.

The results support previous research on the inherent difficulty of providing effective support for close others' stressors (e.g., Rafaeli \& Gleason, 2009; Rini et al., 2006). However, these difficulties were attenuated when providing support for close others' positive events. Despite there being no differences in intended support, there were differences in perceived support. Thus, it seems that the capitalization context is an easier one in which to provide effective, responsive support to others than the traditional social support context. One reason that it is more difficult to convey responsiveness in the negative event context than the positive event context is because the stress associated with the negative event may serve as a filter through which the actual behavior of the provider is perceived (Reis \& Shaver, 1988); this type of filter would narrow and negatively skew the interpretation of the partner's behavior (e.g., Lazarus, 1991). However, positive emotion has been shown to broaden perspectives, and perhaps in the positive event context, this filter may positively skew the interpretation of the partner's behavior (e.g., Fredrickson, 1998). Knowing that responsive support is more difficult to convey in the negative event context than the positive context, we now turn to the question of consequences. What are the implications of higher versus lower perceived responsiveness to the sharing of events, and do these consequences vary by the context of event type?

\section{Study 2}

We designed Study 2 to examine how the quality of responses to event disclosures affected recipients' personal outcomes (e.g., wellbeing) and their interpersonal outcomes (e.g., relationship satisfaction). We assessed perceived responsiveness to the self in each type of disclosure and used that to predict outcomes. We specifically hypothesized that when the partner's reply to a negative event disclosure was perceived as less responsive than average, we would see decreases in interpersonal and intrapersonal outcomes (i.e., risks) compared with days they did not disclose a negative event. We also predicted that when the partner's reply to a positive event disclosure was perceived as less responsive than average, we would see a decrease in interpersonal and intrapersonal outcomes (i.e., risks) compared with days they did not disclose a positive event; however, the pattern would be less severe than for negative events. We reasoned that failures to respond well to a distressed person could exacerbate the stress, but failures to respond well to a happy person could result in the loss of growth opportunity.

\section{Method}

Participants and procedure. Sixty-seven heterosexual cohabiting couples completed the study. ${ }^{6}$ Their mean age and years living together was 25.16 years $(S D=6.33)$ and 1.80 years $(S D=$ 2.46), respectively; $23.9 \%$ were married. During the first session,

\footnotetext{
${ }^{6}$ See Study 2 analysis for a replication of this effect in a different cohabiting sample.
} 
couples came to the lab for an intake session that lasted approximately $1 \mathrm{hr}$. They completed background questionnaires and received instructions and materials for the daily experience portion of the study. For the next 14 days, participants completed a brief questionnaire each night before going to bed. They were instructed to do so independently and privately; prior to leaving the session, they discussed the logistics of how this would be done with the experimenter. After completing each night's entry, participants placed the form in an envelope, sealed the envelope, and stamped the date and time across the seal with an electronic stamper with a security-coded lock (Fuligni \& Hardway, 2006). Each participant was provided with his or her own secured date and time stamper. After 14 days, participants returned to the lab and completed a brief exit measure, were debriefed, and received \$30. Participants completed a total of 1,768 records on time, for an average of 12.36 per person.

\section{Measures.}

Daily event disclosures. Participants were asked whether they had shared a negative event or personal concern with their partner that day and whether they had shared a positive event with their partner that day. Participants only reported events that happened outside of their relationship (e.g., at work), and not events that happened in the relationship (e.g., a conflict, joint activity). If participants did not share a personal negative event with their partner that day, they were instructed to select "N/A = Did not talk about this." They followed the same procedure when reporting personal positive events. There were four types of days in our sample: days in which no event type was shared $(n=563)$, days only a negative event was shared $(n=538)$, days only a positive event was shared $(n=185)$, and days both types of events were shared $(n=482)$.

Participants who shared either type of event during the day were asked three questions about their partner's response to their event disclosure. These three questions were identical to the items used in Study 1: "When I told my partner about a concern/positive event ...": "my partner understood me," "my partner made me feel like he/she valued my abilities and opinions," and "my partner made me feel cared for" using a 5-point scale ranging from 1 (not at all) to 5 (very much). The three questions were averaged together to form a composite; $M=4.04, S D=1.00$ for negative events, and $M=4.25, S D=0.86$ for positive events. Participants shared a total of 1,020 negative events with their partners (an average of 7.61 events per person), and they shared of total of 667 positive events with their partners (an average of 4.97 events per person). ${ }^{7}$

\section{Personal outcomes.}

Anxiety. Four items to assess daily anxiety-anxious, stressed, upset, and scared-were used with a 5-point scale ranging from 1 (not at all) to 5 (extremely). A mean sum of the four items was used to assess daily anxiety $(M=1.97, S D=0.78)$.

Happiness. Four items to assess daily happiness-happy, joyful, excited, and elated-were used. Participants were asked how each term described how they felt today using the same response scale as the anxiety items. A mean sum of these items was used to assess daily happiness $(M=2.86, S D=0.97)$.

Satisfaction with life. Diener and colleagues' five-item scale to assess daily satisfaction with life was used (Diener, Emmons, Larsen, \& Griffin, 1985). The items were "Today, in most ways, my life is close to my ideal"; "Today, the conditions of my life are excellent"; "Today, I am satisfied with my life"; "Today so far, I have gotten the important things that I want in life"; and "Today, if I could live my life over, I would change almost nothing." Participants were asked to what extent they agreed or disagreed with the above statements using a 7-point scale ranging from 1 (strongly disagree) to 7 (strongly agree). A mean sum of these items was used to assess daily satisfaction with life $(\alpha=.93, M=$ 4.51, $S D=1.43$ ).

Composite personal well-being. The correlations among the three personal outcome measures were examined. The Happiness and Life Satisfaction scales were strongly correlated $(r=.58)$. However, the Anxiety scale was only moderately correlated with happiness and life satisfaction ( $r \mathrm{~s}=-.31$ and -.37 , respectively). Therefore, a composite personal well-being scale was created by combining the Happiness and Life Satisfaction scales $(M=3.69$, $S D=1.07$; range $=1.00-6.00)$. The anxiety measure was retained as a separate dependent measure. This separation of personal outcomes is consistent with previous work that has found that daily positive and negative emotional states are largely independent (e.g., Gable, Reis, \& Elliot, 2000).

\section{Relationship quality outcomes.}

Relationship satisfaction. Satisfaction was measured with two items. The first item was used in previous research (e.g., Gable, Reis, \& Downey, 2003): "Today our relationship was" followed by a 9-point scale, with 1 labeled Terrible, 5 labeled $O . K$., and 9 labeled Terrific. The second item was "I felt happy with our relationship," and participants responded with the extent they agreed today using a 5-point scale ranging from 1 (very little or not at all) to 5 (very much). The two items were highly correlated ( $r=$ .70). A composite was created by averaging the two items $(M=$ 5.73, $S D=1.16$ ).

Connection. Feelings of connection were assessed with two items: "I felt out of touch and disconnected from my partner" (reversed) and "I felt accepted by my partner and connected to him/her." Participants were asked how each item described how they felt about their relationship today, and they responded using a 5-point scale ranging from 1 (very little or not at all) to 5 (very much). The two items were strongly correlated $(r=.62)$, so a mean of the items was created to asses daily connection to the partner $(M=4.29, S D=0.90)$.

Security. Feelings of security were also assessed because several researchers have noted the differences between feeling connected or satisfied versus feeling safe and secure in one's relationship (e.g., Rempel, Ross, \& Holmes, 2001). Four items were used to measure security: "I felt secure in our relationship," "I felt that my partner was very trustworthy," "I felt that I could rely on my partner," and "I felt safe in our relationship." Participants responded using the same scale described above for the connection measure, and a mean of the items was created $(M=$ 4.52, $S D=0.71)$.

\footnotetext{
${ }^{7}$ Participants shared fewer positive events with their partners than negative events. However, studies that include entire social networks (e.g., Study 3 of the present article) have shown that people share at least one positive event with others on about $75 \%-85 \%$ of days (Gable \& Reis, 2010). Thus, participants were likely sharing their positive events with a wider array of those in their network than negative events. We return to this point in the Discussion. In addition, any positive event that occurred with the partner was not included in the study protocol.
} 
Composite relationship quality. The correlations among the three relationship outcome measures were examined, and they were strongly correlated ( $r \mathrm{~s}=.67, .72, .78)$. Therefore, a single composite Relationship Quality scale was created by averaging the three relationship outcome measures $(M=4.84, S D=0.84$; range $=1.00-8.00)$.

Reliability of daily measures. For the daily measures, the reliability was calculated using multilevel modeling procedures outlined in Nezlek and Gable (2001; see also Cranford et al., 2006). Specifically, three-level models of items nested within days nested within persons were calculated. Of interest here are what Nezlek and Gable referred to as "within-day reliabilities" and what Cranford et al. referred to as "reliability (between-persons) of measures taken on the same fixed day," as this is analogous to a measurement reliability coefficient. All of the measures showed adequate reliability. Coefficients were as follows: .82 for negative responsiveness, .84 for positive event responsiveness, .90 for anxiety, .93 for the personal well-being composite, and .90 for the relationship quality composite.

\section{Results}

Data analytic strategy. We used three-level hierarchical linear modeling (HLM; Bryk \& Raudenbush, 1992) to analyze the data, with days nested within persons and persons nested within couples. ${ }^{8}$ In order to test our hypotheses regarding gains and risks, we wanted to compare the effects of responsiveness to an event disclosure (high or low) with a baseline. We defined this baseline as days in which neither type of event was shared. We also wanted to compare the effect of low responsiveness to negative event disclosures with the effect of low responsiveness to positive event disclosures, and also compare the effect of high responsiveness to negative event disclosures with the effect of high responsiveness to positive event disclosures.

To test these two sets of predictions, we created four dummy codes. The first code indicated whether the participant shared a negative event and the partner's response was rated at or below the participant's own average for negative events across the days. This was the "low negative event responsiveness" effect code. The second code indicated whether the participant shared a positive event and the partner's response was rated at or below the participant's own average for positive events across the days. This was the "low positive event responsiveness" effect code. The third code indicated whether the participant shared a negative event and the partner's response was rated above the participant's own average for negative events across the days. This was the "high negative event responsiveness" effect code. Finally, the fourth code indicated whether the participant shared a positive event and the partner's response was rated above the participant's own average for positive events across the days. This was the "high positive event responsiveness" effect code. It is important to note that we used the participant's own average responsiveness for negative events only (and not the sum of responsiveness for negative and positive events) to code negative event responsiveness and the participant's own average responsiveness for positive events only to code positive event responsiveness. We did this because we already know from Study 1 (and subsequent analyses of these data presented below) that, on average, responses to negative events are rated lower than those to positive events. In short, we are ruling out Study 1 findings as an explanation for any effects observed in the present analyses. In addition, because we created the dummy codes using deviations from one's own mean, effects cannot be attributed to between-person differences in average ratings of the partner's responsiveness.

We then created a model in which the outcome (e.g., anxiety) was predicted by the intercept and the four uncentered dummy codes representing the four possible event sharing outcomes (low or high responsiveness for each event type) at Level 1 (the day). At Level 2 (the person), we controlled for the person's average level of perceived responsiveness to events by entering the average rating of event responsiveness across the study as a grand meancentered moderator of the intercept. ${ }^{9}$ We constructed three separate equations, one for each outcome measure (anxiety, well-being composite, relationship quality composite).

An example equation follows: Level 1

Anxiety $_{\mathrm{ij}}=p_{0 \mathrm{j}}+p_{1 \mathrm{j}}$ (low negative event responsiveness)

$$
\begin{aligned}
& +p_{2 \mathrm{j}}(\text { low positive event responsiveness }) \\
& +p_{3 \mathrm{j}}(\text { high negative event responsiveness }) \\
& +p_{4 \mathrm{j}}(\text { high positive event responsiveness })+e_{\mathrm{ij}}
\end{aligned}
$$

Level 2

$$
\begin{aligned}
& p_{0 \mathrm{j}}=B_{00}+B_{01} \text { (average responsiveness) }+r_{0} \\
& p_{1 \mathrm{j}}=B_{10}+r_{1} \\
& p_{2 \mathrm{j}}=B_{20}+r_{2} \\
& p_{3 \mathrm{j}}=B_{30}+r_{3} \\
& p_{4}=B_{30}+r_{4}
\end{aligned}
$$

\footnotetext{
${ }^{8}$ There has been some discussion about the optimal way to analyze diary data from couples. One way is a two-level no-intercept model in which daily data from both members of the pair are at Level 1 (days nested within person and person crossed with couple); coefficients of men and women are estimated separately but simultaneously at Level 1 (see Barnett, Raudenbush, Brennan, Pleck, \& Marshall, 1995), and couple is accounted for at Level 2. The other is a three-level model in which days are nested within person, and person is nested within couple. However using a two-level model to analyze the present data would have been problematic because in such a two-level model, only data from days that each member of the couple shared the same type of event with one another would have been included in the model; all other days would be missing (e.g., she shared a positive event but he did not). Moreover "no event" day would be difficult to define.

${ }^{9} \mathrm{We}$ first ran models in which a random coefficient was free to vary on the intercept and the four slopes (r) at Level 2 and the intercept at Level 3. The final models were ones in which we set random coefficients that were nonsignificant in the initial models to zero. We also ran models controlling for the previous day's outcome to address possible autocorrelation issues. Including or excluding random coefficients or controlling for the autocorrelations did not alter the results.
} 
Level 3

$$
\begin{aligned}
& B_{00}=G_{000}+U_{00} \\
& B_{01}=G_{010} \\
& B_{10}=G_{100} \\
& B_{20}=G_{200} \\
& B_{30}=G_{300} \\
& B_{40}=G_{400} .
\end{aligned}
$$

In this model, the intercept $\left(p_{0 \mathrm{j}}\right)$ is the average level of anxiety on days that no events were shared with the partner (for the person at the mean on average responsiveness ratings), $p_{1 \mathrm{j}}$ is the average difference in anxiety between no-sharing days and days a negative event was shared and the partner was rated as low in negative event responsiveness, $p_{2 \mathrm{j}}$ is the average difference between nosharing days and days a positive event was shared and the partner was rated as low in positive event responsiveness, $p_{3 j}$ is the average difference in anxiety between no-sharing days and days a negative event was shared and the partner was rated as high in negative event responsiveness, and $p_{4 \mathrm{j}}$ is the average difference between no-sharing days and days a positive event was shared and the partner was rated as high in positive event responsiveness. In addition, we tested whether the negative and positive lowresponsiveness coefficients were significantly different from one another and whether the negative and positive high-responsiveness coefficients were significantly different from one another using contrast procedures in HLM that use a Wald's test to estimate a chisquare value with one degree of freedom.

Including each person's average responsiveness ratings across the study as a Level 2 moderator of the intercept controlled for any differences in no-sharing days attributable to partners' responsiveness. This further aided in separating between- and within-person effects. Finally, we first ran models including gender as a moderator of the intercept and slopes in the three equations. Gender significantly moderated one of the 15 coefficients tested (one intercept and four slopes in each of the three models). Therefore, we present results from the pooled analyses, and gender is not discussed further. ${ }^{10}$

Event disclosures. Our basic hypotheses were that on days partners' responses were perceived to be less responsive than usual, participants would report decreases in their personal and interpersonal outcomes relative to the baseline of nonsharing days; on days partners' responses were perceived to be more responsive than usual, participants would report increases in their personal and interpersonal outcomes relative to the baseline of nonsharing days. However, our critical hypotheses were that the effect of low responsiveness would be less severe in the positive event context than in the negative event context (i.e., the less risk hypothesis) but that the effect of high responsiveness would be more severe in the positive event context than the negative event context (i.e., the greater gain hypothesis). The coefficients and statistical tests are reported in Table 2 and graphically depicted in Figure 1; these findings were taken from three separate models-one equation for each outcome. Although for clarity we discuss the findings for perceiving low responsiveness from the findings for perceiving high responsiveness separately in the following section, it is im- portant to note that low and high responsiveness were simultaneously analyzed.

Perceiving low responsiveness. As depicted on the left panel of Figure 1, on days participants perceived low responsiveness to negative event disclosures, they reported significantly higher anxiety, and significantly lower well-being and relationship satisfaction than days they did not share any events. In contrast, perceiving low responsiveness when sharing a positive event was not associated with negative outcomes. Specifically, on days participants perceived low responsiveness to positive event disclosures, they reported significantly lower anxiety and significantly higher wellbeing than days they did not share any events; participants' relationship quality did not differ significantly from no-sharing days. Moreover, comparisons of the effects of low responsiveness for the two different types of event disclosures (negative vs. positive) were statistically significant $(p<.05)$ for each of the outcomes. This means that the effect of low responsiveness for negative events was significantly worse (more anxiety, lower well-being and relationship quality) than the effect of low responsiveness for positive events. In sum, perceiving low responsiveness when sharing a negative event was particularly detrimental to personal and relationship outcomes, but perceiving low responsiveness to a positive event disclosure was not.

Perceiving high responsiveness. As depicted on the right panel of Figure 1, on days participants perceived high responsiveness to negative event disclosures, they still reported significantly higher anxiety and significantly lower well-being than days they did not share any events. However, when participants perceived high responsiveness to a negative event disclosure, they did report greater relationship quality than days they did not share an event. In contrast, perceptions of high responsiveness when sharing a positive event were associated with beneficial outcomes on all three measures. Specifically, on days participants perceived high responsiveness to positive event disclosures, they reported significantly lower anxiety and significantly higher well-being and relationship quality than days they did not share any events. Again, comparisons of the effects of high responsiveness for the two different types of event disclosures (negative vs. positive) were statistically significant $(p<.05)$ for each of the outcomes. This means that the effect of high responsiveness for positive events was significantly more beneficial (bigger decreases in anxiety, bigger boosts to well-being and relationship quality) than the effect of high responsiveness for negative events.

Conceptual replication of Study 1 . A major hypothesis that was supported in Study 1 was that participants would perceive more responsiveness from their partners when they shared a positive event than a negative event. This could also be tested on the present data. To parallel the analyses in Study 1, we averaged the perceived responsiveness scores to positive and negative events across days and conducted a paired samples $t$ test on the couple's average scores. Study 2 data replicated Study 1 data, such that positive event interactions were perceived as significantly more responsive than negative event interactions $(M=4.24$ vs. $M=$ 4.01), $t(66)=5.18, p<.001$. Additional paired samples $t$ tests

\footnotetext{
${ }^{10}$ In the one significant gender difference, both men and women showed the same pattern of results on a slope, and both were significantly different from zero; however, women showed a stronger slope than men.
} 
Table 2

Results of Multilevel Models for Negative and Positive Event Disclosures in Study 2

\begin{tabular}{|c|c|c|c|c|c|c|c|c|c|c|c|c|c|}
\hline \multirow[b]{2}{*}{ Outcomes } & \multirow{2}{*}{$\begin{array}{c}\text { Intercept } \\
\text { (no-sharing days) }\end{array}$} & \multicolumn{2}{|c|}{$\begin{array}{l}\text { Low } \\
\text { responsiveness } \\
\text { negative event } \\
\text { coefficient }\end{array}$} & \multicolumn{2}{|c|}{$\begin{array}{c}\text { Low } \\
\text { responsiveness } \\
\text { positive event } \\
\text { coefficient }\end{array}$} & \multicolumn{2}{|c|}{$\begin{array}{c}\text { Comparison } \\
\text { of pos./neg. } \\
\text { low resp. } \\
\text { coefficients }\end{array}$} & \multicolumn{2}{|c|}{$\begin{array}{l}\text { High } \\
\text { responsiveness } \\
\text { negative event } \\
\text { coefficient }\end{array}$} & \multicolumn{2}{|c|}{$\begin{array}{l}\text { High } \\
\text { responsiveness } \\
\text { positive event } \\
\text { coefficient }\end{array}$} & \multicolumn{2}{|c|}{$\begin{array}{c}\text { Comparison } \\
\text { of pos./neg. } \\
\text { low resp. } \\
\text { coefficients }\end{array}$} \\
\hline & & Value & $t, p$ & Value & $t, p$ & $x^{2}$ & $p$ & Value & $t, p$ & Value & $t, p$ & $x^{2}$ & $p$ \\
\hline \multicolumn{14}{|l|}{ Personal } \\
\hline Anxiety & 1.83 & .42 & $7.9,<.001$ & -.12 & $2.7,<.01$ & 49.54 & $<.001$ & .30 & $6.1,<.001$ & -.20 & $3.8,<.01$ & 42.8 & $<.001$ \\
\hline Personal well-being & 3.68 & -.39 & $6.2,<.001$ & .23 & $3.6,<.01$ & 41.9 & $<.001$ & -.11 & $2.1,<.05$ & .46 & $7.1,<.001$ & 40.1 & $<.001$ \\
\hline \multicolumn{14}{|l|}{ Interpersonal } \\
\hline Relationship quality & 4.85 & -.41 & $6.6,<.001$ & .07 & $1.3, .17$ & 34.9 & $<.001$ & .13 & $3.3,<.01$ & .25 & $4.7,<.001$ & 4.8 & $<.05$ \\
\hline
\end{tabular}

Note. Low responsiveness = Days event type was shared and partners' responsiveness was rated at or below the participants' own mean rating of responsiveness for that event type. High responsiveness = days event type was shared and partners' responsiveness was rated above the participants' own mean rating of responsiveness for that event type. $T$ tests on the two coefficients test whether the average outcomes on low (or high) responsiveness days were significantly different from the average outcomes on days no events were shared. Chi-square tests the difference between to the two coefficients for responsiveness. The $d f$ for intercepts $=66$, slopes with random coefficients $d f=133$; slopes without random coefficients $d f=1758$. Personal well-being is a composite of Happiness and Life Satisfaction scales; Relationship quality is a composite of relationship satisfaction, security, and connection. pos. = positive; neg. = negative; resp. = responsiveness.

showed the same results separately for men and women. Positive event responsiveness was rated as higher, on average, than negative event responsiveness for both genders $(M=4.10$ vs. $M=$ $3.96), t(54)=2.16, p<.05$, for men; $(M=4.37$ vs. $M=4.04)$, $t(66)=5.43, p<.001$, for women. Note that because we categorized responsiveness as high or low separately for each event type based on the person's own average for that type of event, this effect cannot account for the findings presented above.

\section{Discussion}

The results of Study 2 were consistent with our predictions. In short, perceived responsiveness to positive and negative event disclosures showed different patterns of risks and gains for both personal and relationship outcomes. When participants shared a

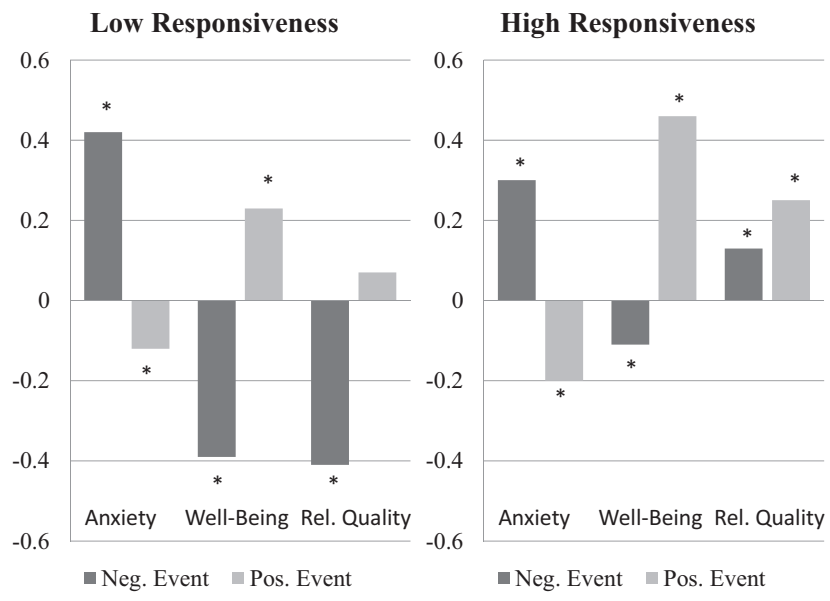

Figure 1. Study 2: Results of hierarchical linear modeling equations of social support and capitalization transactions predicting daily personal and relationship outcomes. ${ }^{*} p<.05$ and tests the hypothesis that the effect is significantly different from baseline (days no events were shared). Rel. = Relationship; Neg. = Negative; Pos. = Positive. negative event and perceived low responsiveness, they showed decrements in personal and relationship outcomes, compared with days they did not share any events, and these decrements were substantial (see Figure 1). On days they perceived high responsiveness when sharing a negative event, participants continued to report less well-being and more anxiety than on no-sharing days but less than when they shared a negative event and perceived low responsiveness. It should be noted that anxiety and negative affect are the primary responses to the occurrence of a negative event (e.g., Gable, Reis, \& Elliot, 2000) and thus most likely were directly affected by the event itself. However, even highly responsive reactions to a negative event disclosure could not return participants to their baseline levels of anxiety and well-being.

Participants did gain in relationship quality when perceiving high responsiveness to a negative event disclosure. Thus, relationship benefits clearly were possible in the traditional social support context when responsiveness was high; however, these relationship gains were significantly smaller than the gains observed with high responsiveness to positive event disclosures. The relationship gains and modest personal gains associated with highly responsive enacted negative event support are somewhat tempered by the substantial risk of support transactions perceived to be low in responsiveness.

This pattern of findings is consistent with previous work that has not measured level of responsiveness and has found either a weak association or a negative association between enacted support and outcomes for the recipient of that support. It should be noted that the pattern was quite different for positive event disclosures. Perceptions of lower than average responsiveness were not associated with decrements in the personal or relationship outcomes compared with no-sharing days. In fact, even when responsiveness was low, well-being was higher, anxiety was lower, and relationship quality was the same as no-sharing days. Moreover, perceptions of high responsiveness were consistently associated with large gains in both personal and relationship outcomes. In short, for positive event disclosures, the gains were substantial and the risks were minimal. 
Thus from the support provider's perspective, reacting less than optimally to a partner's negative event disclosure may contribute to the recipient feeling worse about himself or herself and the relationship than a day an event was not shared, but reacting less than optimally to a positive event disclosure carries less risk. In addition, reacting optimally to a positive event disclosure may contribute to the recipient feeling better about himself or herself and the relationship than baseline, whereas reacting optimally to a negative event may only contribute to him or her feeling better about the relationship.

Previous researchers have argued that one reason that enacted social support (for negative events) can be associated with poor outcomes is that it can bring extra costs and risks to the recipient (e.g., Sarason et al., 1997; Shrout et al., 2006). This study shows that this is especially so when responsiveness is low. When partners provided support that was perceived as low in responsiveness, it seemed to exacerbate the personal distress associated with the negative event. Moreover, providing support that was perceived as low in responsiveness was associated with additional risks to the relationship. Again, these risks were not seen for positive event disclosures, even when responsiveness was perceived as low.

It is also important to note here that our definition of low responsiveness is very conservative. We defined low responsiveness as days in which the perceived level of responsiveness was at or below the person's average (and across participants, this was 4.04 for negative events and 4.25 for positive events, both on a 5-point scale). Examination of the actual mean level of responsiveness reported on days categorized as low in responsiveness was $3.37(S D=0.56)$ for negative events and $3.88(S D=0.72)$ for positive events. Again, both of these averages were well above the midpoint on the scale, and thus our results do not reflect the risks associated with perceiving a particularly poor response, just not a great one.

Confounding of event occurrence and responses to the event. One caveat of Study 2 (and Study 1) is that we did not ask participants about negative events or positive events they did not share with the partner. Thus, we could not compare outcomes on days that an event occurred but was not shared with outcomes on days that an event occurred and was shared with the partner. In this study, we also did not ask participants to rate the importance of the event they shared. In short, our effects of responsiveness are confounded with the occurrence of the event itself, and these events likely varied in their importance, which also likely influenced outcomes. However, as in Study 1, we argue that this "confound" is an important part of the process of interest and that people, such as our participants, also have a difficult time separating their events from partners' responses to the events. In Study 1 , we reasoned that part of the explanation for why responsiveness is harder to convey in the negative event exchange is because the recipient is in distress and sees the exchange through a negative lens; similarly, positive emotions may facilitate benevolent interpretations through positive biases. To test this idea more formally, we conducted an additional analysis in which we compared the average responsiveness ratings to events on days when only that event type was shared with the average rating on days the other event type was shared in a $2 \times 2$ repeated measures analysis of variance. We found the interaction between event valence (positive or negative) and day type (alone or with other event type) was significant, $F(1,66)=14.32, p<.001$. Examination of means showed that positive event responsiveness was rated higher on days only a positive event was shared $(M=4.43, S E=0.06)$ than days a negative event was also shared $(M=4.27, S E=0.08)$. However, negative event responsiveness was rated lower on days only a negative event was shared $(M=3.96, S E=0.09)$ than days a positive event was also shared $(M=4.18, S E=0.08)$.

Here in Study 2, we again propose that the distress associated with the negative event occurrence "contaminates" the interaction and changes the effect it has on important outcomes, and the positive affect associated with the occurrence of the positive event "contaminates" its effect on outcomes. An occasional poor response to a negative event may be especially hard to take when the expectation is high that the partner will be there when things go wrong (e.g., kicking me when I am down). However, an occasional poor response to a positive event exchange may be more easily dismissed or our participants may have turned to someone else to share their good news.

Nonetheless, one could argue that on days people had a negative event, their personal well-being was lower due to the event (and positive events would lead to higher well-being), and it has little to do with partners' responsiveness. However, in taking this position, there is no reason to predict the different pattern of results for well-being we see across the two contexts as a function of partner's responsiveness (e.g., low responsiveness to negative events was associated with a dip below baseline, but low responsiveness to positive events was associated with higher well-being than baseline). More importantly, the personal event causing the change from baseline explanation does not address changes in relationship quality. These events were personal, not relationship events. Moreover, why would sharing a negative event and perceiving low responsiveness be associated with lower relationship quality compared with no-sharing days but similar lower responsiveness (i.e., deviations from one's average perception of responsiveness) in the positive event context leaves one with the same relationship quality as no-sharing days? Similarly, why would perceiving high responsiveness to sharing a positive event lead to a gain in relationship quality that is nearly twice in magnitude (.25) than the same higher responsiveness in the negative event context (.13)? We argue that the explanation is that event valence does indeed contaminate both the interpretation of the partner's intended responsiveness (Study 1) and moderates the effect that perceived responsiveness has on outcomes (Study 2). Future work needs to address exactly what processes are at work here, and we return to this point in the broader Discussion section.

In summary, Study 2 supported our hypothesis that social support provision for negative events (compared with positive events) carries with it additional risks, both for the recipient and for the relationship between the recipient and provider, and the gains are somewhat modest, especially for the personal outcomes. Thus, it is particularly important that traditional social support is perceived as responsive and effective (Rafaeli \& Gleason, 2009). However, as we saw in Study 1 (replicated also in Study 2) and as several researchers have argued, it is very difficult to provide effective and responsive support to stressful events (e.g., Dunkel-Schetter \& Bennett, 1990; Rini et al., 2006). Taken together, Study 1 and Study 2 have shown that providing traditional social support has risks when this support is seen as unresponsive, risks that are not present in the capitalization context. Moreover, traditional support is more likely to be seen as less responsive than capitalization 
support. Thus, in the context in which the stakes are high and getting it right is critical, it is more difficult to get it right. However, we have so far only examined episodes of enacted support and have not considered the overall perceived availability of quality support, which is the measure that has been most consistently associated with positive outcomes in the mental and physical health literature. In the final study, we turn our attention to the perceived availability of support for stressors. Given the inherent risks and difficulties associated with enacted support for negative events, in Study 3 we see whether enacted support for positive events may ironically contribute more to perceptions of the availability of support for stressors than actual support for negative events.

\section{Study 3}

We designed Study 3 as a preliminary test of the hypothesis that instances of responses to positive event disclosures would contribute to perceptions of the quality and availability of support for stressors more than instances of responses to negative event disclosures. In short, we predicted that capitalization interactions would be more strongly related to traditional support quality perceptions than actual instances of that very support. To examine this, we asked participants to describe the responses of others using existing measures of capitalization responses and social support behaviors to their disclosure during a diary study every day for 2 weeks. We then used this as a snapshot of the enacted support quality and enacted capitalization response quality. Two months later, participants reported on the general perceived quality of their social support network during times of stress.

\section{Method}

Participants and procedure. Seventy-six (20 men, 56 women) people from the University of California, Los Angeles community participated in the study. Their ages ranged from 17 to $53(M=22.3, M d n=21)$, and they were ethnically diverse: $35 \%$ Asian, 1\% Black, 8\% Hispanic, 52\% White, and 4\% described themselves as "other." Potential participants responded either to an advertisement in the campus newspaper or to one of several fliers placed around the college and medical center. Participants attended an introductory session in the laboratory to complete the initial questionnaires and received instructions on the daily experience segment of the study. During the daily experience segment, they completed a short questionnaire online each day for 14 days; they were sent reminder e-mails if they failed to complete measures 2 days in a row. Participants returned to the lab approximately 2 weeks later to receive a payment of $\$ 20$ for full participation, which was prorated for partial participation. Two months later, participants were e-mailed (or sent regular mail if requested) a follow-up survey; if they did not respond, they were sent reminders each week for an additional month. They were mailed a $\$ 5$ gift certificate to the campus bookstore upon completion of the follow-up questionnaire. Fifty participants (13 men, 37 women) completed the follow-up survey.

Initial session and follow-up measures.

Perceived quality of typical social support responses. What previous researchers have referred to as instrumental, informational, and emotional support was assessed to measure the per- ceived quality of the social support network at Time 1 and Time 2 . These constructs were tapped by using Barbee and Cunningham's (1995) coping assistance model, specifically, their two approachbased dimensions, solve (problem focused) and solace (emotion focused). Participants' instructions were:

Please take a moment to consider how your social network (family, friends, roommates, romantic partner) typically responds when you tell them about something bad that has happened to you. For example, imagine that you tell them about receiving a criticism at work, having an argument with someone, not getting a raise, losing a sporting match, or failing an exam at school or project at work.

As a frame of reference, we asked them to consider what was typical in the past month. They rated each item using the stem, "In the last month, when I told people in my social network about something bad that has happened to me ..." using a 7-point scale, with 1 labeled Never occurred/Not true of any of my social network and 7 labeled Occurred all of the time/True of all of my social network.

Three questions assessed solve behaviors: "They provided information to help me with the problem/event"; "They gave me resources (e.g., money, time, skills) to help me with the problem/ negative event"; and "They provided me with advice on how to deal with the problem/negative event." Three questions assessed solace behaviors: "They pointed out that I am a good person despite this problem/negative event"; "They expressed interest or concern for my well-being"; and "They comforted me." A composite measure of the six items was created to produce one score that assessed the quality of the social network members' responses to social support attempts. Reliability was good, Time 1 ' $\alpha=.77$ and Time $2^{\prime} \alpha=.84$. Time 1 and Time 2 support quality were moderately correlated $(r=.32, p<.05)$.

Daily measures.

Negative events. Each day, for 14 days, participants briefly described the most important problem or stressful event of the day (if any) and whether or not they told anyone in their social network about the personal negative event. Participants reported telling someone about a negative event an average of 7.5 days $(S D=$ 3.84). They were asked how important the event was $(1=$ not at all, $5=$ a great deal). If they told someone about their negative event, they were then asked to indicate the extent that the person they told provided solve and solace support using the following two items: "He/she provided information or resources to help you with the problem/stressful event" and "He or she pointed out that you are a good person despite this problem/stressful event" $(1=$ not at all, $5=$ a great deal). An average of negative event importance across the 14 days $(M=3.50, S D=0.73)^{11}$ and an average of enacted social support for negative events across the 14 days $(M=2.48, S D=0.66)$ were created.

Positive events. Participants were asked to briefly describe the most important positive event or issue of the day (if any) and whether they told someone about the event. Participants told someone about their positive events an average of 7.32 days $(S D=$ 3.92). They were asked to indicate how important the event was using the same scale they used to rate negative event importance

\footnotetext{
${ }^{11}$ Means and standard deviations for daily measures calculated from 50 participants who completed the follow-up.
} 
$(M=3.60, S D=0.60)$. If they told someone about the event, they were asked to rate that person's response using modified items from Perceived Reactions to Capitalization Attempts scale that have been used in previous research (Gable et al., 2004). The four items assessed the four different behavioral responses to capitalization attempts identified in previous research: activeconstructive ("He/she reacted to my good fortune enthusiastically"), active-destructive ("He/she pointed out the potential problems or downsides of the good event"), passive-constructive ("They said little, but I knew he/she was happy for me"), and passive-destructive ("He/she seemed disinterested"), using the same 5-point response scale that was used for negative event support $(1=$ not at all, $5=$ a great deal $)$. As in previous research (Gable et al., 2006, 2004) and because active-constructive behaviors have consistently been associated with positive outcomes and passive or destructive responses are associated with negative outcomes, a composite measure was created by subtracting the average of the three destructive/passive items from the activeconstructive item. This produced one score that assessed the quality of the enacted capitalization response $(M=1.86, S D=$ 0.77).

Satisfaction with life. As in Study 2, Diener's (1996) fiveitem scale was used to assess daily satisfaction with life. Participants were asked to what extent they agreed or disagreed with the five items using a 5-point scale ranging from 1 (not at all) to 5 (a great deal). A mean sum of these items was used to assess daily satisfaction with life $(\alpha=.92, M=2.60, S D=0.72)$.

\section{Results}

Preliminary analyses. Unlike Studies 1 and 2, in the present data set, we did not measure perceived responsiveness to event disclosures. Instead, we assessed responses to disclosures with well-established measures of the perceptions of behaviors. Therefore, before we proceeded to test our main hypotheses, it was critical to determine whether these behaviors were viewed positively by the participants when enacted, as they indeed have been in past research. ${ }^{12}$ However, in lieu of direct measures of responsiveness, we needed to examine the association between high solve and solace reactions to negative event disclosures and high active-constructive reactions to positive event disclosures with daily outcomes. To do this, we examined the correlations between the average life satisfaction score across the study and the averages of the two event reaction measures. We found that higher daily life satisfaction was associated with higher solve and solace reactions from others when sharing negative events, $r(76)=.29, p<.05$. Similarly, higher daily life satisfaction was also marginally associated with active and constructive reactions from others when sharing positive events, $r(76)=.20, p=.08$. Thus, we have evidence that our measures of social support and capitalization were associated with positive daily outcomes for the individual. In addition, there was no evidence that some people shared only positive events but not negative events, or vice versa. The number of positive events participants shared was highly correlated with the number of negative events people shared $(r=.84)$. Thus, results cannot be interpreted as stemming from difference between people in their tendency to share one or the other type of event. In addition, average ratings of capitalization and solve/ solace behaviors were strongly correlated at .57 , indicating that evaluation of the quality of responses was at least somewhat similar across contexts and that subsequent results likely do not stem from people sharing different event types with two separate social networks.

Primary analyses. Our primary hypothesis was that daily reports of enacted capitalization support would predict change in perceived quality of the support network for negative events from Time 1 to Time 2 but that daily reports of enacted social support for negative events would not predict change in Time 2 perceived quality of the support network for negative events. It should be noted that this is a conservative test of our hypothesis because our measures of daily enacted support for negative events contained a subset of items from the perceived quality of the support network and thus share measurement overlap. We conducted a hierarchical regression analysis and controlled for gender and the average importance of positive and negative events across the diary study.

We regressed Time 2 perceived quality of social support onto average daily enacted capitalization, average daily enacted support for negative events, positive event importance, negative event importance, Time 1 perceived quality of support, and gender. Please see Figure 2 . The overall model was marginally significant $(R=.49), F(6,43)=2.24, p=.058$. Time 1 perceived quality of support was a significant predictor of Time 2 perceived quality of support (standardized $\beta=.35, p<.05$, unstandardized $b=.38$, $S E=.16$ ). Importantly, we found that daily enacted capitalization was a significant predictor of Time 2 social support quality (standardized $\beta=.32, p<.05$, unstandardized $b=.48, S E=.22$ ). However, enacted social support for negative events was not a significant predictor of change in perceived support quality from Time 1 to Time 2 (standardized $\beta=-.10, p=.55$, unstandardized $b=-.17, S E=.28) .{ }^{13}$

This indicates that the more active-constructive (and less passive or destructive) other people were when participants shared a positive event during the diary study, the more their perceived quality of support for negative events available to them changed in a positive direction from Time 1 to Time 2 .

\section{Discussion}

Study 3 showed that perceptions of the quality and availability of support for stressors was not predicted by earlier reports of the quality of support that was actually received during a recent 2-week period of the person's life. This lack of an

\footnotetext{
${ }^{12}$ For example, in behavioral observation work, Gable and colleagues (2006) and Maisel et al. (2008) found that these behaviors were associated with recipients' perceived responsiveness ratings in positive and negative event discussions.

${ }^{13}$ Although daily enacted capitalization support and daily enacted social support were positively correlated, there was no evidence for suppression effects in that analysis in which capitalization support and enacted social support were entered separately produced the same pattern of results. That is, in a regression equation in which enacted support for negative events was not included, enacted capitalization was a significant predictor of change in Time 2 support availability, but enacted support for negative events was still not a significant predictor when enacted capitalization was not included in the model.
} 


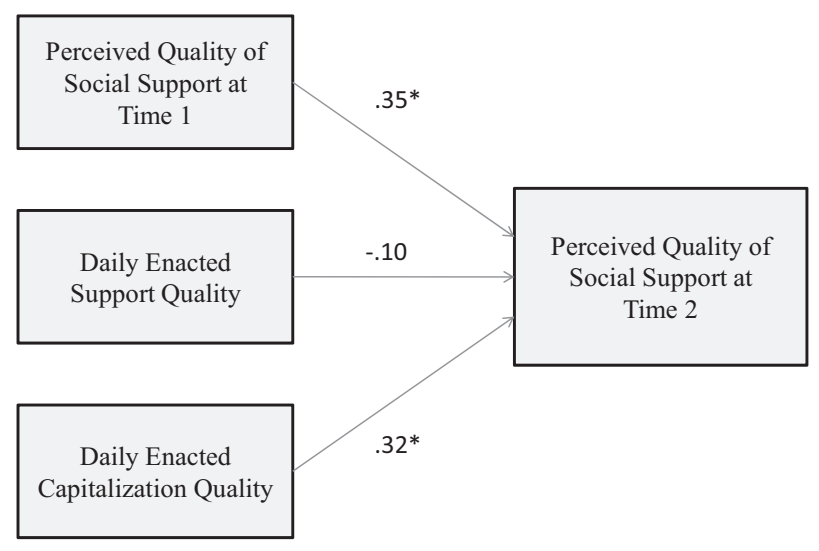

Figure 2. Study 3: Results of full regression model in which Time 1 perceived support quality, daily enacted support for negative events, and daily enacted support for positive events were regressed onto Time 2 perceived support quality. Gender and average importance of positive and negative events were also included in the model as control variables $(R=$ .486), $F(6,43)=2.24, p<.06 .{ }^{*} p<.05$.

association between a measure of enacted support and a measure of the perceived quality and availability of social support in general is highly consistent with previous research and the meta-analysis presented earlier (Haber et al., 2007). This result was also not surprising given the challenges and drawbacks of enacted support that we found in Studies 1 and 2. However, we admit to being somewhat surprised that the association was essentially zero, because the items used to assess daily enacted support were taken directly from the perceived support quality measure.

However, also as we expected, perceived social support quality was positively associated with the quality of enacted capitalization responses during the 2-week daily experience portion of the study. The more participants' friends, families, and partners responded well to their positive event disclosures, the more they perceived they were supportive of them when they had or do have problems or stressful events. Again, this is wholly consistent with our argument that positive exchanges such as capitalization exchanges lay the important foundation of beliefs in people's ability to respond in times of need. Being there in the good times signals a willingness and ability to be there in the bad times.

\section{General Discussion}

Reflecting back on Thomas Jefferson's observation, with which we opened this article, we believe the results of our studies clearly show that relationships are indeed "precious in the sunshine of life." Positive interactions in relationships, such as capitalization exchanges, have not been examined with anywhere close to the empirical vigor that negative interactions, such as conflict and jealously, have been examined (Gable \& Reis, 2001; Reis \& Gable, 2003). Moreover, investigations of the role of close relationships in the stress and coping response have largely been limited to examining support provided under stress, ignoring the larger relational context in which they transpire. It is critical to examine processes that occur outside of actual stress and coping instances to fully understand not only why, when, and how much traditional enacted support will be beneficial and effective but also where perceptions of the quality of available social support come from.

In that vein, our results are consistent with previous studies that have found that enacted support for negative events is not always associated with beneficial outcomes and is sometimes even associated with negative outcomes (e.g., Kaul \& Lakey, 2003). Specifically, we found that support for negative events is only associated with beneficial (or at least not harmful) outcomes when it is perceived as responsive to the self, as suggested by numerous other studies (e.g., Cutrona, 1996; Rafaili \& Gleason, 2009). Moreover, even the benefits or gains associated with highly responsive social support transactions are largely limited to relationship quality improvements and do not elevate individual well-being above baseline. In addition, we found that people feel overall more resentful and misunderstood and less thankful of their partner's support efforts in the negative event context (compared with positive event exchanges), which adds additional consequences of enacted support as suggested by Bolger and colleagues (2000). Most importantly, there are great risks to both personal and relationship health when the support for negative events is perceived as unresponsive.

However, the risks of receiving less responsive support when sharing a positive event are fewer, and the gains of receiving highly responsive support for positive events are great. These gains encompass both individual and relationship benefits. When participants perceived responsive support for their positive events, their personal and relationship well-being went above baseline. When responsiveness was low, their well-being simply returned to baseline (and happiness remained above baseline). In short, although perceptions of low responsiveness to capitalization attempts were not good for the recipient, they also were not harmful. In the moment, it was a win-not lose situation. However, based on past research, we are confident that repeated capitalization responses that are low in responsiveness will erode relationships over time by failing to promote flourishing (e.g., Gable et al., 2006, 2004).

What is clear is that for negative event support, but not positive event support, conveying responsiveness is critical to avoiding leaving the person and the relationship worse off than they were before the interaction. That is, perceptions of highly responsive social support are needed to see relationship gains and avoid personal and relational losses. Unfortunately, our first study showed that responses are more likely to be perceived as less responsive in the negative event context than they are in a positive event context. This is despite the fact that partners intend to provide equally responsive support in both contexts. In addition, because we found that people were seeking equal levels of support in the positive and negative event contexts, violations of expectations are therefore not reasonable explanations for the observed differences in perceived responsiveness. It is quite simply, as others have argued, difficult to provide effective and responsive support when someone close is in distress (e.g., Dunkel-Schetter \& Bennett, 1990; Rini et al., 2006). In our future work, we hope to understand exactly what processes account for this effect. As we outlined in previous sections, we believe that the context of the negative or positive event occurrence itself biases how the support interaction un- 
folds, is perceived, and is encoded in memory-negatively in the former case and positively in the latter.

Lastly, but perhaps most important were our findings regarding perceptions of the quality and availability of the support network. We found, as numerous other studies have found, that enacted social support did not contribute to future perceptions of support quality and availability (e.g., Haber et al., 2007; Lakey et al., 2002; Sandler \& Barrera, 1984). This is despite the fact that the two were measured using variations of the exact same scale items. However, a unique finding in this study is that positive event support (capitalization) did in fact predict future perceptions of support quality and change in support quality perceptions from Time 1 to Time 2 . The more effectively others were perceived to respond during good times was associated with greater perceptions of their ability to respond well in the bad times, and this is consistent with recent findings on the association between general capitalization perceptions and perceived social support (Shorey \& Lakey, 2011). Again, this is extremely relevant to health and well-being because it is the perception that high-quality support is available if needed that is the Holy Grail in terms of its consistent positive associations with health and well-being. Understanding the origins of these perceptions is critical.

In that light, how exactly do perceptions of others' capitalization behaviors transfer to the context of traditional support availability? We feel there are several possible routes. First, a demonstration of concern for one's well-being and growth in good times may generalize to perceptions that one has others who are willing to be available to them more broadly, including when the proverbial rain does fall. Another reason that capitalization processes influence stress-buffering processes is that capitalization responses carry information about how much the responder esteems the recipient. That is, by validating the importance and relevance of the positive event, the responder is essentially saying that the person has worth. And other people care about people with value, even if they later have a problem or stressor.

In the present article, we focused on the situational context (event disclosure type) and not on the effect of dyadic-level differences in relationship quality, including the overall level of responsiveness conveyed in a relationship. It is possible, for example, that overall level of responsiveness could affect evaluations of responsiveness in specific disclosures or the relationship and personal outcomes we examined. In Studies 1 and 2, we did control for this in our analyses, and thus our results cannot be explained by such an effect. However, a related possibility is that in a relationship where responsive support is more common, perceptions of responsiveness might differ less between event type or the occasional slip is not as impactful, or that in a relationship where unresponsive support is common, the occasional responsive reaction is unappreciated or negative event support is particularly problematic. Formally examining the interaction between overall responsiveness in relationships and the context of the particular disclosure is needed to test for these possibilities but was beyond the scope of the present article. ${ }^{14}$ We argue, however, that too often researchers focus on what amounts to dispositional explanations for relationship processes and fail to recognize the impact of the larger environment in which they occur. Despite, for example, findings like those low in socioeconomic status are more vulnerable to myriad negative outcomes, including divorce (e.g., McCleod \&
Kessler, 1990), and processes in health that emphasizes the cumulative effects of a stressful context, such as the allostatic load (e.g., McEwen \& Stellar, 1993), our relationship models largely ignore these important contextual factors as direct contributors to relationship processes. Indeed, we have not fully answered the call put forth by Berscheid (1999) to consider the larger context of life in which the relationship unfolds in our theoretical and empirical models.

\section{Limitations, Future Directions, and Implications}

A limitation of the present set of studies is that we were unable to untangle the effects of behavior from perceptions of that behavior. In all three studies, we measured perceptions of behavior and not the interaction partners' actual behavior. Thus, our conclusions do not address how behavior might be changed to be perceived as more responsive and thus avoid the potential pitfalls and reap the benefits of social support exchanges. In addition, we did not address the likely numerous individual-difference variables and motivations of the recipient that might also act as filter between the responder's behavior and their eventual perceptions of that behavior (e.g., Rini et al., 2006). Future research in both these areas is critical if we want to design interventions aimed at raising perceptions of responsiveness in either the social support or capitalization context.

Another limitation of the present study is that we only addressed how capitalization responses contribute to one aspect of the stress and coping response: the interpersonal resources one feels are available to them. However, because an active-constructive response conveys that the event is important and the discloser did something right; this should also influence feelings of control, self-efficacy, and competence. We base this prediction on a long history in psychology of emphasizing the social aspects of the self, beginning with early theorists such as Cooley (1902) and Mead (1934), who argued that self-evaluation is based on how we imagine that others, especially significant others, evaluate us. Reflected appraisals are part of this process, and more recent work on sociometer theory (Leary, 2005; Leary \& Baumeister, 2000) speaks to this idea. We also know that constructs such as perceived control and self-efficacy beliefs are important resources that predict overall functioning and moderate how people cope with stressors (e.g., Aspinwall \& Taylor, 1992; Taylor \& Stanton, 2007). In particular, studies have shown a relationship between a generalized sense of control and efficacy and better psychological and physical health (Haidt \& Rodin 1999; Karasek, Theorell, Schwartz, Pieper, \& Alfredsson, 1982) and lower mortality (Seeman \& Lewis 1995).

\footnotetext{
${ }^{14}$ We actually tested for this in Studies 1 and 2. In Study 2, we included overall responsiveness as a moderator on the slope between daily responsiveness and outcome. There was no evidence for this type of moderation. In Study 1, we examined the interaction of within-subject differences on perceived responsiveness and a median split on overall responsiveness. The results showed a significant interaction and simple effect analyses that for both couples with high and low levels of responsiveness, they perceived positive event responsiveness more favorably than negative event responsiveness, but this difference was bigger in the low overall responsiveness group.
} 
In addition, situation-specific control and self-efficacy expectations have been shown to be beneficial for managing those stressful events (e.g., Bandura, 2006). Future work should investigate how positive interactions with others influence these important self-related constructs.

Finally, we want to address the take-home message of our findings. Our results do not, by any means, indicate that the traditional social support context is not important to personal and relationship health. Nor should they be interpreted that when approached by a close other in distress, one is better off ignoring the support seeking or avoiding the support seeker, which would no doubt be perceived as highly unresponsive. In fact, laboratory research clearly has shown that highly responsive enacted support can lead to relationship and personal gains (e.g., Collins \& Feeney, 2000; Uchino, Carlisle, Birmingham, \& Vaughn, 2011). ${ }^{15}$ What our findings do suggest is that conveying responsiveness in this context is critical but difficult, and even if done well can still have unintended drawbacks.

More importantly, though, our findings suggest that other nonstressful exchanges have huge implications for personal and relationship well-being. From a support provider's perspective, then, capitalization contexts serve as opportunities to contribute to both flourishing of the relationship and the partner. These capitalization responses can lay a solid foundation that can weather the inevitable storms in life. From an empirical perspective, the implications are also important. For decades the assumption has been that relationships contribute to health and well-being because they protect us from the harmful effects of stressors. Thus, as scientists, we have been looking at the stress and coping context almost exclusively to understand these links. We are missing an entire class of relationship interactions and processes that are likely contributing to health and well-being. Some of these contributions may indeed come from their indirect effect of mitigating stressors. However, the larger picture suggests that there are likely direct effects that these positive processes have on health and well-being. They deserve our careful scientific consideration.

\section{Concluding Comments}

In understanding the role of positive interactions in the stressbuffering process, we have found the analogy of the red button on a smoke detector to be useful. Everyone knows that having a working smoke detector in the home is a good thing, but how do we know that the smoke detector is working efficiently without actually setting a fire? Pushing the red test button is relatively easy, straightforward, and carries no risk. Yet, pushing this button when there is no emergency lets us know the smoke detector will be there if there is a real fire. In relationships, when close others are responsive to our needs consistently during the ups of daily life, it lays a solid foundation of belief in their accessibility during the down times. Positive events are opportunities to push the red button. Why, then, is the pattern of results for enacted support for negative events so different? Here we take the smoke detector analogy one step farther; if there is an actual fire, the stress of the crisis and the aftermath of fire (e.g., clean-up, emotional recovery) may overshadow appropriate appreciation for the properly working smoke detector. Again, in relationships, responding to a partner's stressor, even if it is done well, may not be properly appreciated by that partner due to the demands of the stressor, and even if appreciated may only bring that person back to baseline and not move them beyond that baseline and into the territory of flourishing.

\footnotetext{
${ }^{15}$ Interestingly, the laboratory context may serve to eliminate many of these unintended drawbacks and maximize the likelihood of the response being perceived as effective (e.g., acute, uncontrollable stressors seem to elicit more emotional support; Uchino et al., 2011, and feelings of indebtedness and resentment may be minimized when one partner is assigned to undergo the stressor and the other is assigned to be the supporter).
}

\section{References}

Aspinwall, L. G., \& Taylor, S. E. (1992). Modeling cognitive adaptation: A longitudinal investigation of the impact of individual differences and coping on college adjustment and performance. Journal of Personality and Social Psychology, 63, 989-1003. doi:10.1037/0022-3514.63.6.989

Bandura, A. (2006). Toward a psychology of human agency. Perspectives in Psychological Science, 1, 164-180. doi:10.1111/j.17456916.2006.00011.x

Barbee, A. P., \& Cunningham, M. R. (1995). An experimental approach to social support communications: Interactive coping in close relationships. In B. R. Burleson (Ed.), Communication yearbook (Vol. 18, pp. 381413). Thousand Oaks, CA: Sage.

Barbee, A. P., Derlega, V. J., Sherburne, S. P., \& Grimshaw, A. (1998). Helpful and unhelpful forms of social support for hiv-positive individuals. In V. J. Derlega \& A. P. Barbee (Eds.), HIV and social interaction (pp. 83-105). Thousand Oaks, CA: Sage.

Barnett, R. C., Raudenbush, S. W., Brennan, R. T., Pleck, J. H., \& Marshall, N. L. (1995). Change in job and marital experiences and change in psychological distress: A longitudinal study of dual-earner couples. Journal of Personality and Social Psychology, 69, 839-850. doi:10.1037/0022-3514.69.5.839

Barrera, M., Sandler, I. N., \& Ramsay, T. B. (1981). Preliminary development of a scale of social support: Studies on college students. American Journal of Community Psychology, 9, 435-447. doi:10.1007/ BF00918174

Berscheid, E. (1999). The greening of relationship science. American Psychologist, 54, 260-266. doi:10.1037/0003-066X.54.4.260

Blain, M. D., Thompson, J. M., \& Whiffen, V. E. (1993). Attachment and perceived social support in late adolescence: The interaction between working models of self and others. Journal of Adolescent Research, 8, 226-241. doi:10.1177/074355489382006

Bolger, N., Zuckerman, A., \& Kessler, R. C. (2000). Invisible support and adjustment to stress. Journal of Personality and Social Psychology, 79, 953-961. doi:10.1037/0022-3514.79.6.953

Bryk, A. S., \& Raudenbush, S. W. (1992). Hierarchical linear models: Applications and data analysis methods. Newbury Park, CA: Sage.

Chen, S., Boucher, H. C., \& Tapias, M. P. (2006). The relational self revealed: Integrative conceptualization and implications for interpersonal life. Psychological Bulletin, 132, 151-179. doi:10.1037/00332909.132.2.151

Cohen, S. (1988). Psychosocial models of the role of social support in the etiology of physical disease. Health Psychology, 7, 269-297. doi: 10.1037/0278-6133.7.3.269

Cohen, S., \& Wills, T. A. (1985). Stress, social support, and the buffering hypothesis. Psychological Bulletin, 98, 310-357. doi:10.1037/00332909.98.2.310

Collins, N. L., Dunkel-Schetter, C., Lobel, M., \& Scrimshaw, S. C. (1993). Social support in pregnancy: Psychosocial correlates of birth outcomes and postpartum depression. Journal of Personality and Social Psychology, 65, 1243-1258. doi:10.1037/0022-3514.65.6.1243

Collins, N. L., \& Feeney, B. C. (2000). A safe haven: An attachment theory perspective on support seeking and caregiving in intimate relationships. 
Journal of Personality and Social Psychology, 78, 1053-1073. doi: 10.1037/0022-3514.78.6.1053

Cooley, C. H. (1902). Human nature and the social order. New York, NY: Scribner.

Coyne, J. C., \& DeLongis, A. (1986). Going beyond social support: The role of social relationships in adaptation. Journal of Consulting and Clinical Psychology, 54, 454-460. doi:10.1037/0022-006X.54.4.454

Cranford, J. A., Shrout, P. E., Iida, M., Rafaeli, E., Yip, T., \& Bolger, N. (2006). A procedure for evaluating sensitivity to within-person change: Can mood measures in diary studies detect change reliably? Personality and Social Psychology Bulletin, 32, 917-929. doi:10.1177/ 0146167206287721

Cutrona, C. E. (1996). Social support in couples: Marriage as a resource in times of stress. Thousand Oaks, CA: Sage.

Dakof, G. A., \& Taylor, S. E. (1990). Victims' perceptions of social support: What is helpful from whom? Journal of Personality and Social Psychology, 58, 80-89. doi:10.1037/0022-3514.58.1.80

Diener, E., Emmons, R. A., Larsen, R. J., \& Griffin, S. (1985). The Satisfaction With Life Scale. Journal of Personality Assessment, 49, 71-75.

Dunkel-Schetter, C., \& Bennett, T. (1990). Differentiating the cognitive and behavioral aspects of social support. In B. R. Sarason, I. G. Sarason, \& G. Pierce (Eds.), Social support: An interactional view (pp. 267-296). New York, NY: Wiley.

Fleming, R., Baum, A., Gisriel, M. M., \& Gatchel, R. J. (1982). Mediating influences of social support on stress at Three Mile Island. Journal of Human Stress, 8, 14-23. doi:10.1080/0097840X.1982.9936110

Forster, L. E., \& Stoller, E. P. (1992). The impact of social support on mortality: A seven-year follow-up of older men and women. Journal of Applied Gerontology, 11, 173-186. doi:10.1177/073346489201100204

Fredrickson, B. L. (1998). What good are positive emotions? Review of General Psychology, 2, 300-319. doi:10.1037/1089-2680.2.3.300

Fuligni, A. J., \& Hardway, C. (2006). Daily variation in adolescents' sleep, activities, and psychological well-being. Journal of Research on Adolescence, 16, 353-378. doi:10.1111/j.1532-7795.2006.00498.x

Gable, S. L., Gonzaga, G., \& Strachman, A. (2006). Will you be there for me when things go right? Supportive responses to positive event disclosures. Journal of Personality and Social Psychology, 91, 904-917. doi:10.1037/0022-3514.91.5.904

Gable, S. L., \& Haidt, J. (2005). What (and why) is positive psychology? Review of General Psychology, 9, 103-110. doi:10.1037/10892680.9.2.103

Gable, S. L., \& Reis, H. T. (2001). Appetitive and aversive social interaction. In J. Harvey \& A. Wenzel (Eds.), Close romantic relationships: Maintenance and enhancement (pp. 169-194). Mahwah, NJ: Erlbaum.

Gable, S. L., \& Reis, H. T. (2010). Good news! Capitalizing on positive events in an interpersonal context. In M. Zanna (Ed.), Advances in experimental social psychology (Vol. 42, pp. 198-257). New York, NY: Elsevier. doi:10.1016/S0065-2601(10)42004-3

Gable, S. L., Reis, H. T., \& Downey, G. (2003). He said, she said: A quasi-signal detection analysis of daily interactions between close relationship partners. Psychological Science, 14, 100-105. doi:10.1111/ 1467-9280.t01-1-01426

Gable, S. L., Reis, H. T., \& Elliot, A. J. (2000). Behavioral activation and inhibition in everyday life. Journal of Personality and Social Psychology, 78, 1135-1149.

Gable, S. L., Reis, H. T., Impett, E., \& Asher, E. R. (2004). What do you do when things go right? The intrapersonal and interpersonal benefits of sharing positive events. Journal of Personality and Social Psychology, 87, 228-245. doi:10.1037/0022-3514.87.2.228

Gleason, M. E. J., Iida, M., Bolger, N., \& Shrout, P. E. (2003). Daily supportive equity in close relationships. Personality and Social Psychology Bulletin, 29, 1036-1045. doi:10.1177/0146167203253473

Haber, M. G., Cohen, J. L., Lucas, T., \& Baltes, B. B. (2007). The relationship between self-reported received and perceived social support: A meta-analytic review. American Journal of Community Psychology, 39, 133-144. doi:10.1007/s10464-007-9100-9

Haidt, J., \& Rodin, J. (1999). Control and efficacy as interdisciplinary bridges. Review of General Psychology, 3, 317-337. doi:10.1037/10892680.3.4.317

Helgeson, V. S., \& Cohen, S. (1996). Social support and adjustment to cancer: Reconciling descriptive, correlational, and intervention research Health Psychology, 15, 135-148. doi:10.1037/0278-6133.15.2.135

Holahan, C. J., Moos, R. H., Holahan, C. K., \& Brennan, P. L. (1997) Social context, coping strategies, and depressive symptoms: An expanded model with cardiac patients. Journal of Personality and Social Psychology, 72, 918-928. doi:10.1037/0022-3514.72.4.918

Karasek, R. A., Theorell, T., Schwartz, J., Pieper, C., \& Alfredsson, L. (1982). Job, psychological factors and coronary heart disease: Swedish prospective findings and U.S. prevalence findings using a new occupational inference method. Advanced Cardiology, 29, 62-67.

Kaul, M., \& Lakey, B. (2003). Where is the support in perceived support? The role of generic relationship satisfaction and enacted support in perceived support's relation to low distress. Journal of Social and Clinical Psychology, 22, 59-78. doi:10.1521/jscp.22.1.59.22761

Kenny, D. A., Kashy, D. A., \& Cook, W. L. (2006). Dyadic data analysis. New York, NY: Guilford Press.

Lakey, B., Adams, K., Neely, L., Rhodes, G., Lutz, C. J., \& Sielky, K. (2002). Perceived support and low emotional distress: The role of enacted support, dyad similarity and provider personality. Personality and Social Psychology Bulletin, 28, 1546-1555. doi:10.1177/ 014616702237582

Lakey, B., \& Cassady, P. B. (1990). Cognitive processes in perceived social support. Journal of Personality and Social Psychology, 59, 337343

Lakey, B., \& Orehek, E. (2011). Relational regulation theory: A new approach to explain the link between perceived social support and mental health. Psychological Review, 118, 482-495. doi:10.1037/ a0023477.

Langston, C. A. (1994). Capitalizing on and coping with daily-life events: Expressive responses to positive events. Journal of Personality and Social Psychology, 67, 1112-1125. doi:10.1037/0022-3514.67.6.1112

Lazarus, R. S. (1991). Emotion and adaptation. New York, NY: Oxford University Press.

Leary, M. R. (2005). Sociometer theory and the pursuit of relational value: Getting to the root of self-esteem. European Review of Social Psychology, 16, 75-111. doi:10.1080/10463280540000007

Leary, M. R., \& Baumeister, R. F. (2000). The nature and function of self-esteem: Sociometer theory. In M. P. Zanna (Ed.), Advances in experimental social psychology (Vol. 32, pp. 1-62). San Diego, CA: Academic Press.

Lehman, D. R., Ellard, J. H., \& Wortman, C. B. (1986). Social support for the bereaved: Recipients' and providers' perspectives on what is helpful Journal of Consulting and Clinical Psychology, 54, 438-446. doi: 10.1037/0022-006X.54.4.438

Maisel, N. C., \& Gable, S. L. (2009). The paradox of received social support. Psychological Science, 20, 928-932. doi:10.1111/j.14679280.2009.02388.x

Maisel, N. C., Gable, S. L., \& Strachman, A. (2008). Responsive behaviors in good times and in bad. Personal Relationships, 15, 317-338. doi 10.1111/j.1475-6811.2008.00201.x

McEwen, B. S., \& Stellar, E. (1993). Stress and the individual: Mechanisms leading to disease. Archives of Internal Medicine, 153, 20932101.

McLeod, J. D., \& Kessler, R. C. (1990). Socioeconomic status differences in vulnerability to undesirable life events. Journal of Health and Social Behavior, 31, 162-172. doi:10.2307/2137170 
Mead, G. H. (1934). Mind, self, and society. Chicago, IL: University of Chicago Press.

Murray, S. L., Holmes, J. G., \& Collins, N. L. (2006). Optimizing assurance: The risk regulation system in relationships. Psychological Bulletin, 132, 641-666. doi:10.1037/0033-2909.132.5.641

Nezlek, J. B., \& Gable, S. L. (2001). Depression as a moderator of relationships between positive daily events and day-to-day psychological adjustment. Personality and Social Psychology Bullietin, 27, 16921704. doi:10.1177/01461672012712012

Ognibene, T. C., \& Collins, N. L. (1998). Adult attachment styles, perceived social support and coping strategies. Journal of Social and Personal Relationships, 15, 323-345. doi:10.1177/0265407598153002

Rafaeli, E., \& Gleason, M. E. J. (2009). Skilled support within intimate relationships. Journal of Family Theory and Review, 1, 20-37. doi: 10.1111/j.1756-2589.2009.00003.x

Reis, H. T. (2003). A self-report measure of perceived partner responsiveness. Unpublished data, University of Rochester.

Reis, H. T., Clark, M. S., \& Holmes, J. G. (2004). Perceived partner responsiveness as an organizing construct in the study of intimacy and closeness. In D. J. Mashek \& A. Aron (Eds.), Handbook of closeness and intimacy (pp. 201-225). Mahwah, NJ: Erlbaum.

Reis, H. T., \& Gable, S. L. (2003). Toward a positive psychology of relationships. In C. L. M. Keyes \& J. Haidt (Eds.), Flourishing: Positive psychology and the life well-lived (pp. 129-159). Washington, DC: American Psychological Association. doi:10.1037/10594-006

Reis, H. T., \& Shaver, P. (1988). Intimacy as an interpersonal process. In S. Duck (Ed.), Handbook of personal relationships (pp. 367-389). Chichester, England: Wiley.

Reis, H. T., Smith, S. M., Carmichael, C. L., Caprariello, P. A., Tsai, F.-F., Rodrigues, A., \& Maniaci, M. R. (2010). Are you happy for me? How sharing positive events with others provides personal and interpersonal benefits. Journal of Personality and Social Psychology, 99, 311-329.

Rempel, J. K., Ross, M., \& Holmes, J. G. (2001). Trust and communicated attributions in close relationships. Journal of Personality and Social Psychology, 81, 57-64. doi:10.1037/0022-3514.81.1.57

Rholes, W. S., Simpson, J. A., Campbell, L., \& Grich, J. (2001). Adult attachment and the transition to parenthood. Journal of Personality and Social Psychology, 81, 421-435. doi:10.1037/0022-3514.81.3.421

Rini, C., Schetter, C. D., Hobel, C. J., Glynn, L. M., \& Sandman, C. A. (2006). Effective social support: Antecedents and consequences of partner support during pregnancy. Personal Relationships, 13, 207-229. doi:10.1111/j.1475-6811.2006.00114.x

Rusbult, C. E., Zembrodt, I. M., \& Gunn, L. K. (1982). Exit, voice, loyalty, and neglect: Responses to dissatisfaction in romantic involvements. Journal of Personality and Social Psychology, 43, 1230-1242. doi: 10.1037/0022-3514.43.6.1230

Sandler, I. N., \& Barrera, M. (1984). Toward a multimethod approach to assessing the effects of social support. American Journal of Community Psychology, 12, 37-52. doi:10.1007/BF00896927
Sarason, B. R., Sarason, I. G., \& Gurung, R. A. R. (1997). Close personal relationships and health outcomes: A key to the role of social support. Hoboken, NJ: Wiley.

Seeman, M., \& Lewis, S. (1995). Powerlessness, health and mortality: A longitudinal study of older men and mature women. Social Science and Medicine, 41, 517-525. doi:10.1016/0277-9536(94)00362-W

Shorey, R. C., \& Lakey, B. (2011). Perceived and capitalization support are substantially similar: Implications for social support theory. Personality and Social Psychology Bulletin, 37, 1068-1079.

Shrout, P. E., Herman, C. M., \& Bolger, N. (2006). The costs and benefits of practical and emotional support on adjustment: A daily diary study of couples experiencing acute stress. Personal Relationships, 13, 115-134. doi:10.1111/j.1475-6811.2006.00108.x

Smith, T. W., Ruiz, J. M., \& Uchino, B. N. (2004). Mental activation of supportive ties, hostility, and cardiovascular reactivity to laboratory stress in young men and women. Health Psychology, 23, 476-485. doi:10.1037/0278-6133.23.5.476

Stone, A. A., Mezzacappa, E. S., Donatone, B. A., \& Gonder, M. (1999). Psychosocial stress and social support are associated with prostatespecific antigen levels in men: Results from a community screening program. Health Psychology, 18, 482-486. doi:10.1037/02786133.18.5.482

Taylor, S. E., \& Stanton, A. L. (2007). Coping resources, coping processes, and mental health. Annual Review of Clinical Psychology, 3, 377-401. doi:10.1146/annurev.clinpsy.3.022806.091520

Uchino, B. N. (2009). Understanding the links between social support and physical health: A life-span perspective with emphasis on the separability of perceived and received support. Perspectives on Psychological Science, 4, 236-255. doi:10.1111/j.1745-6924.2009.01122.x

Uchino, B. N., Cacioppo, J. T., \& Kiecolt-Glaser, J. K. (1996). The relationship between social support and physiological processes: A review with emphasis on underlying mechanisms and implications for health. Psychological Bulletin, 119, 488-531. doi:10.1037/00332909.119.3.488

Uchino, B. N., Carlisle, M., Birmingham, W., \& Vaughn, A. A. (2011) Social support and the reactivity hypothesis: Conceptual issues in examining the efficacy of received support during acute psychological stress. Biological Psychology, 86, 137-142. doi:10.1016/j.biopsycho .2010.04.003

Wills, T. A., \& Shinar, O. (2000). Measuring perceived and received social support. In S. Cohen, L. G. Underwood, \& B. H. Gottlieb (Eds.), Social support measurement and intervention: A guide for health and social scientists (pp. 86-135). New York, NY: Oxford University Press.

Received June 14, 2011

Revision received May 21, 2012

Accepted May 23, 2012 